\title{
Side-Effects of Pesticides on the Pollinator Bombus: An Overview
}

\author{
Veerle Mommaerts ${ }^{1,2}$ and Guy Smagghe 2 \\ ${ }^{1}$ Free University of Brussels, Brussels \\ ${ }^{2}$ Ghent University, Ghent
}

Belgium

\section{Introduction}

For the pollination of crops, agriculture relies largely on managed colonies of the honeybee Apis mellifera (Gallai et al., 2009). Unfortunately, recent crashes of colonies have been reported worldwide, also better known as "Colony Collapse Disorder" (CCD) (Mullin et al., 2010). In this context several authors pointed out that factors such as parasites and pesticides or a combination of these factors might be responsible for a decline in honeybee health (Van Engelsdorp et al., 2009). As a response multiple studies were conducted to assess pesticide residues in the field. The results were dramatic. For example, a study of apiaries in North American orchards recovered 121 agrochemicals in honeybees, pollen and the wax (Mullin et al., 2010). However the impact of our agricultural landscape is not limited to honeybee colonies. Indeed, also other pollinators suffer. Since 40 years non-Apis species such as bumblebees are decreasing in abundance (Goulson et al., 2008). Bumblebees, important for the pollination of many wild flowers, are crucial for the terrestrial ecosystem (Goulson, 2010). In addition, these pollinators as Bombus terrestris, Bombus impatiens and Bombus ignitus are also commercially reared for the pollination of agricultural and horticultural crops (Velthuis \& van Doorn, 2006). Therefore, side-effects of pesticides need to be assessed for conservation and economic reasons. However, our current knowledge of pesticide toxicity on pollinating insects is fragmented for bumblebees since it is still mostly restricted to $A$. mellifera. One explanation to this can be found in bumblebees belonging to a less familiar group in the area of environmental protection. To date only a few pesticides have been tested on their compatibility with bumblebees prior to their commercial release, while for honeybees oral and acute toxicity tests are required for pesticide registration. Newer generation pesticides, which are thought to be less harmful to humans and the environment than the older pesticides such as synthetic organophosphate, carbamate and pyrethroid insecticides, are on the current marketplace. Nonetheless, even sublethal effects of pesticides may have significant impact on bees and pollination in addition to the more easily observable mortality.

This chapter provides for the first time an extensive overview of the side-effects of pesticides also called as "Plant Protection Products" (PPPs) on bumblebees. In a first and second part we will discuss the testing strategies so far employed to evaluate pesticide compatibility on bumblebees. Here attention will be given to the different "tier" levels, the various biological endpoints of effect, and the impact of the route of exposure. Then in a third part, an 
overview will be given on the compatibility data that are currently available for the different groups of chemical and biological pesticides such as insecticides, acaricides, fungicides. A fourth part will compare the pesticide sensitivity between both pollinators for the different groups of PPPs. Finally, based on our increasing knowledge on the insect body we will make suggestions to improve some existing tests in order to work more standardized which would allow comparison between different PPPs in future.

\section{Risk assessment at different "tier" levels with individual workers and micro-colonies in the laboratory to full colonies in the field}

When assessing the toxicity of pesticides the first question one should address is: Can exposure to the pesticide occur? In the field, possible routes of exposure for bumblebees are by direct contact after a spray or orally via the consumption of contaminated food. However, evaluating the effect of a single pesticide or residue on an organism under field conditions is complex. However, in the case potential side-effects cannot be excluded, the risks need to be assessed in a stepwise approach with different "tier" levels (Figure 1).
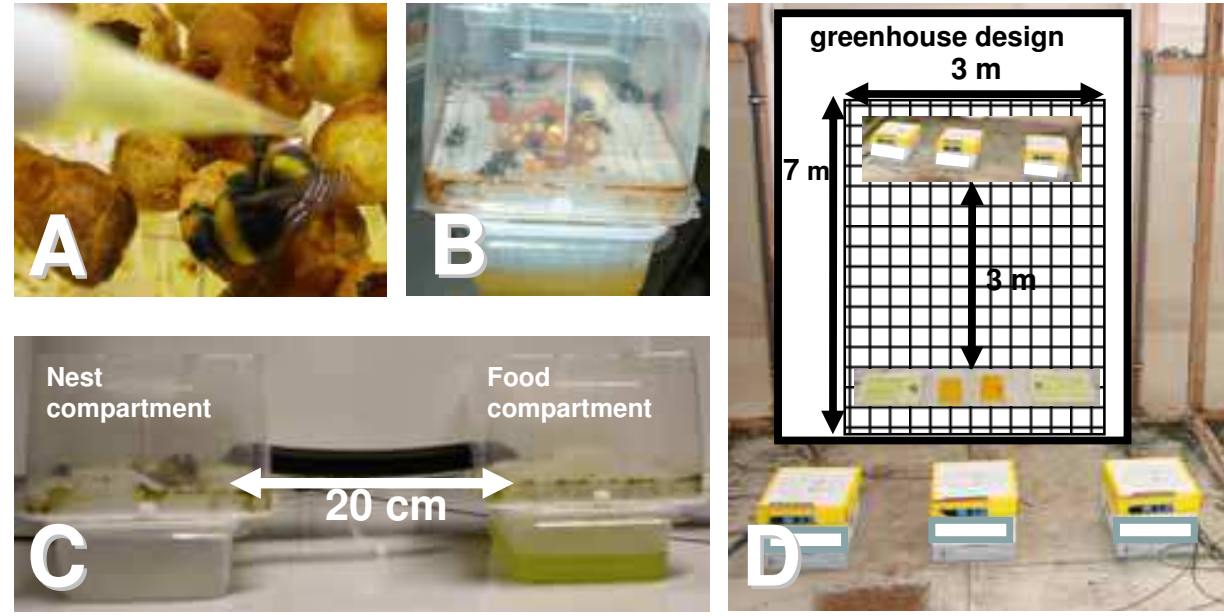

Fig. 1. Schematic overview of the different "tier" levels with (A) individual workers in the laboratory ("tier 1"), (B) micro-colonies in the laboratory without foraging ("tier 2"), (C) micro-colonies in the laboratory including foraging behavior ("tier 2"), and (D) full colonies in small greenhouse compartments ("tier 3 "). The inset of D gives the greenhouse design (3 $x 7 \mathrm{~m}$ ) with the bumblebee colonies placed at $3 \mathrm{~m}$ from the food (own photographs).

At "tier 1" level, individual bumblebee workers are exposed to a worst case scenario in a laboratory insect toxicity test. To assess direct contact toxicity due to a spray application several experimental setups have been used (see for review Thompson, 2001; van der Steen, 2001). Currently, pesticides are dissolved in acetone and worker bumblebees are anesthetized with carbon dioxide up to $7 \mathrm{~s}$ prior to application of specific doses/concentrations to the bumblebee workers. For pesticide application dishes containing individual bumblebee workers are placed under a Potter spray tower (Scott-Dupree et al., 2009; Gradish et al., 2010). After treatment workers are transferred to cups with wax paper 
where they are then provided with fresh sugar water. Then $48-72 \mathrm{~h}$ post-treatment acute toxicity is evaluated and the median lethal dose/concentration $\left(\mathrm{LC}_{50}\right.$ or $\left.\mathrm{LC}_{50}\right)$ is calculated. For this test at least 30 individual bumblebees need to be exposed. Also for the assessment of the acute toxicity via oral exposure, several protocols have been developed over the years (see for review Thompson, 2001). Bumblebees were first starved for 2-3 h and then fed with a $10 \mu \mathrm{l}$ mixture of the pesticide dissolved in $50 \%$ sucrose which they had to consume within $2 \mathrm{~h}$ (see for review van der Steen, 2001). Hereafter the bumblebees were provided with regular sugar water and the $\mathrm{LD}_{50}$ was determined after $24-72 \mathrm{~h}$. In the controls, an acceptable mortality level of $\leq 10 \%$ was set. The same method has also been recently used by Wu et al. (2010). These researchers assessed the oral toxicity in the laboratory with individual workers of the three bumblebee species B. ignitus, Bombus hypocrita and Bombus patagiatus and the diverse pesticides that are frequently used in Chinese greenhouses. In general, acute toxicity studies in the laboratory are easy to perform, but here attention should be given to the age of the individual workers used as susceptibility might change with the worker age. Some studies conduct their risk assessment with callow workers $(<24 \mathrm{~h})$, while others use bumblebees between 9-10 days or do not give any information on how the workers were selected.

A criticism on the aforementioned laboratory risk assessment tests with individual bumblebee workers over $72 \mathrm{~h}$, is that side-effects of pesticides might take a longer time $(>72$ h) before becoming visible under practical conditions and that bumblebee workers show a social organization with the building of a nest (brood) and with foraging behavior to gather food from outside to inside the nest. It is therefore recommended to conduct an extended laboratory test as a second step of the risk assessment ("tier 2"). In order to cover all potential side-effects, bumblebees are exposed as in the insect laboratory test with individual workers ("tier 1") to PPPs concentrations recovered in the field, to concentrations as recommended for use or to the maximum field recommended concentration (MFRC). To date several studies evaluated potential postponed effects up to 11 weeks following exposure to insecticides, acaricides and fungicides by use of micro-colonies (Besard et al., 2010, 2011; Gradish et al., 2010; Mommaerts et al., 2006a,b, 2008, 2009, 2010a,b). Microcolonies are artificial nests made of 3 to 5 workers of the same age, however a number of 5 workers is to be recommended for long chronic exposure assessments (Figure 1B). The wide application of this method in risk assessment studies with bumblebees can be explained by the low cost, the easy in use, the possibility to work standardized and with multiple replicates resulting in statistical power and thus in reproducible data. For the direct contact toxicity all the workers of the nest are treated by contact with a $50 \mu \mathrm{l}$ drop of an aqueous solution made of the pesticide and tap water, on the dorsal thorax. These data give already strong indications on the compatibility of the pesticide with bumblebees, but other routes of exposure also occur. In the past, systemic compounds like neonicotinoids have been recovered in pollen. Also more recently, large studies in Europe and North-America showed the presence of PPP residues in pollen collected by honeybees (Skerl et al., 2009; Mullin et al., 2010; Wu et al., 2011). To simulate an oral chronic exposure via contaminated food, the bumblebee workers in the micro-colonies can be fed continuously with treated food (sugar water and/or pollen) over a period up to 11 weeks, or they can be fed for a period of 30 days after which they are then provided for 30 days with untreated food. For the sugar water treatment a solution is made of commercial sugar water (50\%) or artificial home-made sugar water and the pesticide. Contaminated pollen paste is prepared by spraying pollen until saturation with an aqueous solution of the pesticide, prepared in tap water (Besard et al., 
2010; Mommaerts et al., 2006a,b, 2008, 2009, 2010a). However, the pesticide can also be dosed at exact amounts to pollen grains, which are then mixed with sugar syrup, and finally offered as a homogenous food source to the bumblebee workers. A final route of exposure is via residues left on plant surfaces. To simulate this situation, Wu et al. (2010) sprayed solutions of the pesticide (as prepared in water) on paper which was then air-dried before exposure to the bumblebees. To assess such effect upon exposure to biological insecticides, Hokkanen et al. (2004) developed two different methods. First, by treatment of the flowers until drip-off, and secondly via a "maximum challenge test". In the latter test bumblebee workers walk through a Petri Dish containing the growing and sporulating fungus. Considering the worker mortality, the aim of the extended laboratory tests is to classify PPPs. Unfortunately, criteria for a classification of substances are up until today not available for bumblebees. However, the side-effects' classification for arthropods and beneficial organisms by the "International Organization for Biological Control of Noxious Animals and Plants" (IOBC) is useful: "class 1": <25\% effect, non-toxic; "class 2": 25-50\% effect, weakly toxic; "class 3": 50-75\% effect, moderately toxic; and "class 4": >75\% effect, highly toxic. There is still no validation of this classification at present. For example when a product causes a loss of $<25 \%$, it is considered as not toxic. However, Goulson (2010) argued that the effect of a loss on the colony is directly depending on the colony size. We therefore suggest that in future these classification classes should be defined in relation to the range of the colony size.

Besides worker mortality (i.e. lethal side-effects), risk assessment studies also need to cover potential sublethal side-effects on bumblebee reproduction, larval development and the foraging ability of adults. These parameters are of crucial importance to guarantee the crop pollination. At first colonies containing adult workers and brood were fed on a treated $50 \%$ sugar solution during $24 \mathrm{~h}$. Then, the brood (consisting of egg cups, open cups containing larval and pupal stages) was evaluated by observations at 3 times per week and this over a period of 3 weeks (see van der Steen, 2001). However, collecting data on effects on brood is difficult and thus de Wael et al. (1995) developed a method where the brood was daily checked and by photographing the brood from a fixed point. Although this was already an improvement a better protocol was developed by Gretenkord \& Dresscher (1996). Here a more detailed evaluation was possible as eggs were removed from the colony and incubated until hatching where after the number of larvae was standardized to 10. For exposure, the larvae were placed in small boxes containing 3 workers that fed treated pollen during $24 \mathrm{~h}$. Then, the amounts of pollen consumed by the larvae and the numbers of larvae developing into an adult were determined. Also these sublethal endpoints can be assessed with microcolonies (Mommaerts et al., 2006a,b, 2010a; Gradish et al., 2010), but this will be discussed in more detail under 2.1. Moreover, in "tier 2" also laboratory trials including side-effects on the foraging behavior can be included. For example, Mommaerts et al. (2010b) recently reported on a "foraging bioassay" which made use of micro-colonies. As depicted in figure $1 \mathrm{C}$, a box containing a micro-colony was connected by a tube of $20 \mathrm{~cm}$ in length with an empty nest containing the food (pollen and sugar water). This experimental setup allows the evaluation of interferences with the orientation capacity of the adult bumblebee workers. However, also other endpoints important for the foraging process can become affected after pesticide exposure. Hereto flight cages are a good tool. Morandin et al. (2005) connected colonies to flight cages $(1.2 \mathrm{~m} \times 1.2 \mathrm{~m} \times 1 \mathrm{~m})$ wherein artificial flowers were placed to evaluate the impact of an insecticide on the flower handling time and on the foraging speed. Finally, in a last step, the PPPs are to be tested under semi-field and field conditions ("tier 
3"). The aim of such complex studies is to get more insight in the risks for bumblebee colonies under more practical, field-related conditions. However, up until today the numbers of such studies are limited (see for review van der Steen, 2001). Gretenkord \& Drescher (1996) was the first to describe a protocol for semi-field testing. According to his method a colony of at least 100 workers was placed in a cool box in the ground. Then this box was connected to a gauze tent $(3 \mathrm{~m} \times 2 \mathrm{~m} \times 4 \mathrm{~m})$ containing flowering Phacelia tanacetifolia plants. At a foraging intensity of 10 workers the connection tube is closed, the colony is standardized (containing one queen, 10 foragers, 5 nurses, 4- 6 egg cups, and brood that is consisting of one cup with larval stages of 1-2 days, 3-4 days, and 5-6 days old and with 10-15 pupae), and the plants are sprayed. Bumblebees are exposed during 2-3 weeks and thereafter lethal and sublethal side-effects are assessed during 2 weeks in the laboratory. Similarly, Sechser \& Reber (1996) placed free flying colonies in a tent $\left(5-9 \mathrm{~m}^{2}\right)$ that was sprayed with the recommended concentration of the pesticides, and in addition colonies were fed with sugar water supplemented with the pesticide. Here effects were evaluated on all stages after 6 weeks. Moreover, next to tents, semi-field tests have also been conducted in small greenhouse compartments $\left(3 \mathrm{~m} \times 2 \mathrm{~m}\right.$ ) with a crop area of $2 \mathrm{~m}^{2}$ (Tasei et al., 1993). However, the main problem with the use of crops in small compartments is that the size of the colony is not proportionate to the crop size, resulting in not enough pollen and nectar for the colony. To circumvent the use of plants, as depicted in figure 1D, Mommaerts et al. (2010b) provided bumblebee colonies with commercial pollen and treated sugar water at a distance of $3 \mathrm{~m}$ from their nest in greenhouse risk assessment experiments.

For field testing, a first protocol was described by Schaefer \& Mühlen (1996). They placed six bumblebee colonies in a $2400 \mathrm{~m}^{2}$ field with flowering Phacelia plants. Here worker mortality, colony activity and colony development were evaluated by collecting dead workers, activity observations on $5 \times 1 \mathrm{~m}^{2}$ for $1 \mathrm{~min}$ and by counting adults, dead larvae and photographing the brood. Also here the IOBC classification for side-effects in arthropods and beneficial organisms has been used to classify substances, but again it should be remarked that no validation has been done so far. According to this classification system for (semi-)field

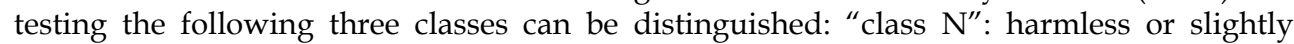
harmful, 0-50\%; "class $\mathrm{M}^{\prime}$ : moderately harmful, 51-75\%; and "class $\mathrm{T}^{\prime}$ : harmful, $>75 \%$. Besides a lack of a proper classification system, it is still unclear how long bumblebees should be exposed. Some studies provide bumblebees during 5 weeks with treated food followed by a period of 5 weeks of uncontaminated food, while in other studies bumblebees were exposed during their entire life-span. Consequently, comparison between the determined risks resulting from the different assessment tests with the same pesticides is difficult.

\subsection{Different biological endpoints for the assessment of side-effects}

At present, risk assessments for PPPs follow regulatory guidelines which are for Europe defined by the European Council Directive 91/414. The aim of these guidelines is to protect honeybees and other pollinators. Here only side-effects on adult and larvae of honeybees are considered, while exposure in the field to other pollinators cannot be excluded. For example bumblebees might be exposed to pesticides in greenhouses through spraying via residues left on plants or by consuming contaminated nectar and pollen. Following exposure, the most obvious effect is worker mortality, but pesticides may also cause sublethal effects. Moreover, due to the increasing development of chemicals with different modes of action there is a demand to define valuable endpoints of effects. At present the increasing 
economic importance of bumblebees in agriculture results in a growing body of literature on side-effects of pesticides of which on overview is given below.

\subsubsection{Lethal effects}

For a long time risk assessment studies with bees only considered the $\mathrm{LD}_{50}$ or $\mathrm{LC}_{50}$ of pesticides. Most likely this approach is probably based on honeybee risk assessments where at first the risk was calculated by the hazard quotient which is the application rate divided by the $\mathrm{LD}_{50}$ as calculated after $72 \mathrm{~h}$ of exposure (i.e. "tier 1"). To date for acute worker mortality, insect death (i.e. lethal endpoint) which is easy to observe, is not adequate enough. Indeed, the lethal dose is only a partial assessment of the risk for loss of survival as the test runs only for 3 days. Therefore Gradish et al. (2010) scored workers as dead when they did not move upon touching. This criterion considers also the effect of slower acting pesticides such as for the pesticides abamectine and metaflumizone that causes paralysis of the insect, resulting in feeding cessation and death. In conclusion, to date acute toxicity (via oral and contact exposure) is evaluated on the level of individual insects, whereas studies evaluating the long term side-effects (i.e. chronic exposure) make use of micro-colonies of bumblebees. It is to be noticed that the latter experimental setup has the wide advantage to consider potential pesticide transfer between bumblebees which might occur upon contact.

\subsubsection{Sublethal effects}

Considering the growing interest to determine potential sublethal effects following pesticide exposure, several methods have been reported to identify and characterize these for beneficial arthropods. A first comprehensive review on this research topic was published by Desneux et al. (2007). Here the authors mainly focused on effects on honeybees and natural enemies. However, the use of bumblebees in agriculture demands for examinations of sublethal side-effects as pollination must be guaranteed. For bumblebees, the reported sublethal effects of pesticides include effects on adults and on brood with fecundity and abnormal larval development resulting in reduced offspring. More details are discussed hereunder.

\subsection{Exposure to different developmental stages 2.2.1 Exposure to adult workers}

Following pesticide exposure, adults can directly be affected. At first adult longevity was shown affected after exposure to lethal and/or sublethal concentrations. For example Gradish et al. (2010) observed a shortened life-span when adult workers were fed on imidacloprid-treated pollen by scoring the number of dead workers.

So far pesticide exposure occurs in long-term studies by feeding the bees with contaminated food. For bumblebees food consumption is crucial as workers need sugar water for energy and pollen for ovary development (Heinrich, 1979). Based on this often also a second endpoint has been evaluated, namely, worker biomass. To determine worker biomass, some studies determined the weight of collected dead workers, while others used newly emerged workers which were cooled before weighed (Gradish et al., 2010; Wu et al., 2010).

Moreover, considering the importance of food for ovary development the moment of first oviposition has been used as a third endpoint. Care is needed as a reduction of the fecundity (oviposition) can be the result of a reduced food uptake or of a physiological effect of the pesticide. For example for diflubenzuron (IGR), Mommaerts et al. (2006a) showed 
transovarial transport and accumulation in the eggs after pollen consumption by adults resulting in egg mortality. Next to a reduction, pesticides can also induce a stimulatory effect on the oviposition. Topical contact of adult workers with a sublethal concentration of kinoprene (IGR) resulted in a significant increase of both ovarian length and the numbers of eggs present in the ovaries (Mommaerts et al., 2006b).

Finally, pesticides are known to induce behavioral changes on adults (Thompson, 2003). To date several studies demonstrated that ingestion of small amounts of pesticides (e.g. imidacloprid, deltamethrin) by adult honeybees (Colin et al., 2001; Decourtye et al., 2003) interferes with their learning and orientation capacity. Similarly, sublethal concentrations of imidacloprid affected bumblebee behavior as Mommaerts et al. (2010b) demonstrated with use of the "foraging bioassay", thus when adult bumblebees (B. terrestris) needed to gather their food, that adult bumblebees had difficulties to find back the way to their nest resulting in a severe reduction of the offspring. For foragers orientation and memory are essential to find food. Assessment of these side-effects occurs in honeybees by use of the proboscis extension response (PER) (Decourtye \& Pham-Delègue, 2002; Decourtye et al., 2004a,b; El Hassani et al., 2008). However, for bumblebees PER has been conducted with Bombus occidentalis but not in the context of risk assessments (Riveros \& Gronenberg, 2009). Therefore future studies might include this method to broaden the endpoints which might become affected when adult bumblebees are exposed to pesticides.

\subsubsection{Exposure to eggs, larvae and pupa}

Bumblebee foragers gather pollen and nectar which is transported to the hive. Pesticides can also be brought to the hive via this route. Thus, in the field bumblebee brood can become indirectly exposed to pesticides sprayed on crops when the brood (larvae) is fed with contaminated pollen/nectar. For the assessment of these side-effects micro-colonies have been used successfully. In micro-colonies, comprising of 3 to 5 callow workers, one worker becomes dominant and starts to lay eggs after one week, while the other workers assist her in rearing the brood. Eggs laid in micro-colonies are not fertilized and will develop over 4 larval stages and 1 pupal stage into male adults (drones) after 4 weeks. Effects on brood are scored as the numbers of larvae that are removed from the brood. This criterion is based on the typical behavior of bumblebee workers to remove larval stages with abnormalities or dead larvae from the respective brood clump (Mommaerts et al., 2006a,b, 2009, 2010a; Gradish et al., 2010). Moreover, this endpoint was further refined in accordance with the mechanism of action of pesticides under investigation. For example, in case of the IGRs as developed to interfere with the developmental processes in insects, the different stages of the removed larvae were determined based on their head width (Mommaerts et al., 2006a,b). For effects on the reproduction, the number of offspring (drones) produced was already used by multiple studies as endpoint (Mommaerts et al., 2006a,b, 2008, 2009, 2010a,b; Besard et al., 2010, 2011). Here drones were measured on a weekly basis and this during a period up to 11 weeks; the drones were removed from the micro-colonies after scoring.

Considering behavioral effects, Morandin et al. (2005) showed that spinosad (insecticide) when administered during the entire larval stage affected other parameters crucial for the foraging capacity of adult workers. Hereto the authors connected a bumblebee (B. impatiens) colony with a flight cage, containing two different types of artificial flowers. A "simple flower" consisted of an Eppendorf tube without caps, while a "complex flower" an Eppendorf tube with the caps attached leaving an opening of $7 \mathrm{~mm}$. With this experimental setup data were collected on the time period needed to access the first artificial flower, the 
handling time, and the foraging rate. However, there exists a debate to date whether sublethal effects must be investigated, particularly at lower tier level, because potential sideeffects are expected to become visible in experiments at higher tier level. It should be noted that there is not enough information to make a firm conclusion in this matter.

Next to indirect exposure via food, only a few studies examined the effect of a direct contamination of the brood by contact. For example Mommaerts et al. (2008) treated thirdand fourth-instar larvae by dermal contact with a suspension of a biological insecticide in water to assess the larval toxicity of the compound. Also van der Steen (2005) evaluated side-effects on bumblebee brood. Hereto all adult workers were removed from the colony prior to spraying.

\section{Different classes of pesticides}

\subsection{Chemical pesticides \\ 3.1.1 Insecticides}

To date risks assessment studies conducting the side-effects of conventional insecticides are mostly limited to acute toxicity studies. A summary of all available data on effects of the older insecticides including the pyrethroids, the carbamates and the organophosphates is given in table 1. Interestingly, van der Steen (1994) found that the acute toxicity (oral and contact) for dimethoate was correlated with the size of the bumblebee. In addition, for the pyrethroid deltamethrin also sublethal effects have been described. At double the recommended rate, Gretenkord \& Drescher (1993) reported a repellent effect. Similarly, Tasei et al. (1994) showed an increase of $40-100 \%$ in sucrose uptake when $B$. terrestris were treated by dermal contact with $0.08-0.16 \mathrm{mg} / \mathrm{kg}$, whereas a higher dose of $0.1-0.2 \mathrm{mg} / \mathrm{kg}$ caused a $47-59 \%$ decrease of sucrose uptake. Overall, when considering conventional insecticides it is remarkable that none of all compounds included $(n=59)$ was considered as non-toxic (Figure 2).

Neonicotinoids are systemic insecticides which interfere with the insect nervous system by binding on the nicotinic acetylcholine receptor. The most studied compound within this group is imidacloprid. Exposure to bumblebees (B. terrestris or B. impatiens) caused acute worker mortality after contact/oral exposure (Incerti et al., 2003; Marletto et al., 2003; ScottDupree et al., 2009; Gradish et al., 2010; Mommaerts et al., 2010b). Also effects such as bumblebee trembling, reduced brood production, pollen consumption, vitality, and impaired foraging behavior have been observed after exposure to imidacloprid (Tasei et al., 2000; Gels et al., 2002; Incerti et al., 2003; Morandin \& Winston, 2003; Gradish et al., 2010). However Tasei et al. (2001) concluded by use of a greenhouse test that imidacloprid when applied as a seed coating at the registered dose did not affect $B$. terrestris foraging and homing behavior. Although imidacloprid received much attention in risk assessments, this group of neonicotinoids also contains other compounds. Recently, Mommaerts et al. (2010b) reported that the neonicotinoids with a nitro group (imidacloprid and thiamethoxam) caused the greatest side-effects. Here it should also be remarked that not only the mother product but also metabolites were shown to affect bee survival. For example clothianidin, derived from thiamethoxam, was highly toxic after contact on B. impatiens workers. In contrast, acetamiprid and thiacloprid both belonging to the group of the cyano-neonicotinoids, were less toxic. In total only $17 \%$ of the 6 compounds considered were safe (Figure 2).

IGRs are classified as more selective due to their interference with insect-specific targets however only $47 \%$ of the compounds tested has been found non-toxic (Figure 2). Within the IGRs, three different groups can be distinguished: chitin synthesis inhibitors (CSIs), juvenile 
hormone analogs (JHAs), and ecdysteroid agonists or also called molting-accelerating compounds (MACs).

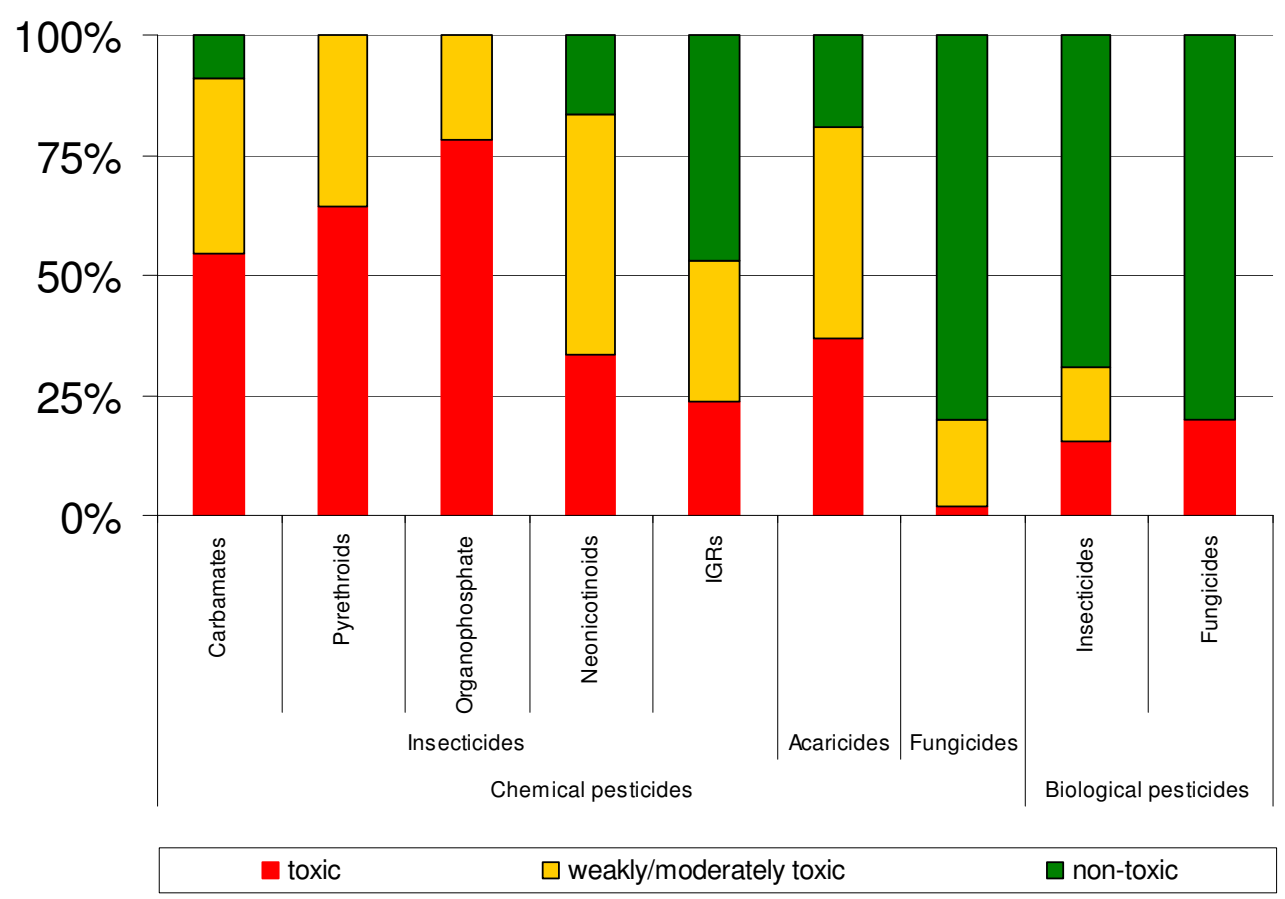

Fig. 2. Overview of the toxicity of chemical and biological pesticides towards bumblebees (Bombus terrestris). For each pesticide group the bars represent the percentage of compounds which are non-toxic (green), weakly/moderately toxic (yellow-orange) and toxic (red). The division in toxicity levels is based on the recommendations made by the side-effect list when available, or on the obtained toxicity with micro-colonies ("tier 2"). The numbers of compounds considered per group are $n=11$ for carbamates, $n=14$ for pyrethroids, $n=32$ for organophosphates, $\mathrm{n}=6$ for neonicotinoids, $\mathrm{n}=17$ for IGRs, $\mathrm{n}=13$ for biological insecticides, $\mathrm{n}=27$ for acaricides, $\mathrm{n}=66$ for chemical fungicides, and $\mathrm{n}=5$ for biological fungicides. For details with references, see table 1, 2 and 3 .

CSIs are mainly larvicides and act through the inhibition of chitin formation. So far no mortality was reported by CSIs against adult bumblebee workers (de Wael et al., 1995; Tasei, 2001; Mommaerts et al., 2006a; Scott-Dupree et al., 2009). However, severe effects have been observed on reproduction. Dermal contact exposure to the MFRC of diflubenzuron (288 $\mathrm{mg} / \mathrm{l})$ and teflubenzuron $(150 \mathrm{mg} / \mathrm{l})$ caused a total inhibition of adult formation (Mommaerts et al., 2006a). Also for diflubenzuron transovarial transport was confirmed. The NOEC for this compound was 100-10,000 times lower than the MFRC. Consequently, it is not recommended to use these compounds in combination with bumblebees. Other CSIs tested comprise novaluron, flucycloxuron, flufenoxuron, lufenuron, buprofezin and cyromazine (Mommaerts et al., 2006a; Scott-Dupree et al., 2009). Here the route of exposure will determine the effect with the strongest effects seen when CSIs were administrated via 
the pollen. Overall, the MFRC of all CSIs were also detrimental to larval growth as significantly more larvae of the first and second instar were removed due to an abnormally formed cuticle.

The JHAs with a function resembling the juvenile hormone $(\mathrm{JH})$, are contact and stomach poisons. In insects, $\mathrm{JH}$ is responsible for the regulation of the metamorphosis and the synthesis of vitellogenin. For B. terrestris toxicity tests by use of micro-colonies showed that JHAs (pyriproxyfen, fenoxycarb and kinoprene) did not cause acute/chronic worker mortality by oral/contact exposure (Mommaerts et al., 2006b). Similarly, no effect on the reproduction was reported when $B$. terrestris workers were exposed during 11 weeks to the MFRC of these compounds. In contrast, pollen exposure to pyriproxyfen $(25 \mathrm{mg} / \mathrm{l})$ and kinoprene $(650 \mathrm{mg} / \mathrm{l})$ resulted in a significantly higher numbers of removed third- and fourth-instar larvae, implying a lethal blockage of the development before metamorphosis (Mommaerts et al., 2006b). Interestingly, for the latter compound a low concentration of $0.0650 \mathrm{mg} / 1 \mathrm{had}$ a stimulatory effect on brood production, resulting in longer ovaries that contained more eggs than in control dominant workers.

The MACs are active after contact and ingestion when they bind on the receptor site of the insect molting hormone 20-hydroxyecdysone, the ecdysone receptor. For the bumblebee $B$. terrestris the MFRC of tebufenozide and methoxyfenozide did not affect worker survival, worker reproduction and larval development (Mommaerts et al., 2006b). In conclusion, the extended laboratory tests with micro-colonies indicated that these MCAs are compatible with the use of bumblebees.

Finally, within the class of the chemical insecticides metaflumizone, chlorantraniliprole and a natural plant derivate Matrine (Kingbo) have also been tested. These insecticides are currently used in the greenhouse vegetable production. For metaflumizone $0.1-1 \mathrm{~g} / 1$ caused direct contact toxicity, whereas chorantraniliprole was harmless (Gradish et al., 2010). Also both insecticides at the recommended rate did not affect reproduction in $B$. impatiens microcolonies (Gradish et al., 2010). The natural plant derivate Matrine was only evaluated for its impact on worker survival. After contact exposure to dry residues Wu et al. (2010) observed a significant effect on worker mortality when application doses used in the greenhouse were tested $(1 / 5000, \mathrm{v} / \mathrm{v})$. For oral toxicity it was interesting that the $\mathrm{LD}_{50}$ for B. hypocrita $(0.0019$ $\mu \mathrm{g}$ per bee) was significantly higher than for the other bumblebee species (B. ignitus and $B$. patagiatus) (Wu et al., 2010).

\subsubsection{Acaricides}

Studies evaluating the impact of acaricides are limited. Recently Besard et al. (2010) published a first extensive evaluation of 23 acaricides (traditional and novel ones) on $B$. terrestris by using the laboratory micro-colony design. Also here effects are different according to the route of exposure with the strongest effects observed after oral exposure via the drinking of treated sugar water. According to Besard et al. (2010) abamectin, bifenazate, bifenthrin and etoxazole were not compatible with $B$. terrestris. At a concentration of 18 mg/l (i.e. MFRC) abamectine caused 100\% worker loss. Similarly, Gradish et al. (2010) reported for $B$. impatiens $80-100 \%$ worker mortality after contact to $0.1-1.0 \mathrm{~g} / 1$ while oral exposure via pollen caused several sublethal effects such as reduced colony lifespan and delay of oviposition. Overall, of the 27 compounds tested only $19 \%$ was non-toxic (see figure 2). For more detailed information concerning the different acaricides so far tested see table 2 . 


\subsubsection{Fungicides}

Risk assessments including fungicides are limited resulting in only fragmented data (see table 3). Overall, it can be concluded that at the recommended rates the fungicides tested (myclobutanil, potassium bicarbonate, difenoconazole and copper abietate) did not cause a negative effect on $B$. impatiens worker survival and reproduction. Also the side-effect list (see Biobest side-effect list: http://www.biobest.be, and Koppert side-effect list: http://neveneffecten.koppert.nl/), comprising data of more than 50 active ingredients of applied fungicides, recommends that bumblebee hives do not need to be removed before product application, however except for carbendazim, cyprodinil+fludioxonil, dimethomorph, fosetyl-aluminium, penconazole, pyrazofos and tebuconazole. Here it is recommended to remove the hives prior to application and this until $24 \mathrm{~h}$ after. On this list only one active ingredient, namely zineb (Zerlate), is indicated as not compatible. Consequently, of the 66 compounds included $66 \%$ is classified as non-toxic (Figure 2).

\subsubsection{Weed crop control products and plant growth/health regulators}

To our knowledge no data is available at present on the compatibility with bumblebees of herbicides, plant growth regulatory hormones (e.g. straw shorteners) and plant health stimulating compounds, such as chemicals that induce systemically acquired resistance (SAR) in the treated crops.

\subsection{Biological pesticides}

\subsubsection{Bio-insecticides}

The group of the biological insecticides includes 13 different compounds of which $69 \%$ is considered as safe (Figure 1).

Beauveria bassiana GHA and Metarhizium anisopliae caused side-effects on B. terrestris (Hokkanen et al., 2004; Mommaerts et al., 2009). In the laboratory contact exposure to $2.5 \mathrm{x}$ $1010 \mathrm{CFU} / 1$ (i.e. MFRC) of B. bassiana GHA resulted in $92 \%$ worker mortality after 11 weeks, while oral administration did not affect worker survival. In addition, also sublethal effects on the reproduction and changes in the foraging behavior have been observed with $B$. bassiana GHA (Mommaerts et al., 2008, 2009).

For the MFRC of Cydia pomonella granulovirus no detrimental effects have been observed after contact and oral exposure (Mommaerts et al., 2009).

In the laboratory with the micro-colony design no worker mortality was seen after contact and oral exposure via eating pollen to the MFRC of Bacillus thuringiensis kurstaki and $B$. thuringiensis aizawai (Mommaerts et al., 2010a). In contrast, oral exposure via sugar water treated with $B$. thuringiensis aizawai caused a $100 \%$ loss, but this effect disappeared when the concentration was 10 times diluted. Similar effects were also reported on $B$. occidentalis and B. terrestris by Morandin \& Winston (2003) and Babendreier et al. (2008) when pure Cry proteins (Cry1 Ab and Cry1Ac) were taken up via pollen and sugar water. Concerning the sublethal effects on reproduction var. kurstaki was harmless, while var. aizawai administered at $0.01 \%$ via the pollen reduced reproduction by $31 \%$. Both strains did not induce behavioral changes.

For the naturalyte spinosad, consisting of spinosyn A and D derived from the fermentation of the bacterium Saccharopolyspora spinosa, acute oral and contact toxicity tests demonstrated its toxicity for bumblebees (Mayes et al., 2003). However, according to Morandin et al. (2005) colony losses only occurred when bumblebees (B. impatiens) were exposed to an unrealistically high dose of $8.0 \mathrm{mg} / \mathrm{kg}$. Nonetheless, at realistic field concentrations $(0.2-0.8$ 
$\mathrm{mg} / \mathrm{kg}$ ) sublethal effects were observed. For example larval exposure to $0.8 \mathrm{mg} / \mathrm{kg}$ via the diet (pollen) resulted in adults foraging slower on artificial complex flowers, whereas such effects were not visible at lower concentrations. Similarly, Besard et al. (2011) demonstrated for $B$. terrestris that oral feeding with the MFRC ( $400 \mathrm{mg} / \mathrm{l}$ ) of spinosad caused $75 \%$ worker mortality after $72 \mathrm{~h}$. Here bumblebee workers showed tremors causing paralysis and finally insect death. Moreover, at $0.4 \mathrm{mg} / 1$ spinosad was harmless. In contrast, the novel spinosyn spinetoram was less toxic as the MFRC ( $25 \mathrm{mg} / \mathrm{l})$ resulted only in $55 \%$ worker mortality. No sublethal effects were scored at $0.025 \mathrm{mg} / \mathrm{l}$. In addition, a wet and dry residue test also confirmed the higher toxicity of spinosad over spinetoram.

\subsubsection{Bio-fungicides}

In total the MFRC of 5 different microbiological fungicides have been tested with the microcolony design (see table 3). All were classified as harmless via the different routes of exposure, except Bacillus subtilis QST713 (Figure 2). Here the MFRC (7.5 x $\left.10^{9} \mathrm{CFU} / \mathrm{l}\right)$ resulted in a severe total loss of adult $B$. terrestris workers ("class 4 " for extended laboratory testing) after contact and oral exposure to treated sugar water (Mommaerts et al., 2009).

\section{Sensitivity for pesticide side-effects: does there exist a correlation between honeybees and bumblebees?}

To determine the sensitivity for pesticide side-effects between closely related pollinators as $B$. terrestris and A. mellifera we will first compare the overall toxicity of the different classes of PPPs. Then, for the chemical insecticides we will investigate if a correlation exists on product level between bumblebee and honeybee toxicity by use of a regression analysis with available $\mathrm{LD}_{50}-24 \mathrm{~h}$. Finally, for the insecticides such as the IGRs whereof no $\mathrm{LD}_{50}$ could be found the side-effects on bumblebees were compared with those on honeybees.

As mentioned above the toxicity of different PPPs for bumblebees is given in figure 2. At present toxicity data of all PPPs are available for honeybees. An overview of the relative toxicity based on the $\mathrm{LD}_{50}-48 \mathrm{~h}$ after contact and oral exposure on honeybees (A. mellifera) for the different classes of PPPs (the same selection of PPPs as for figure 2) is given in figure 3. Comparison of both figures 2 and 3 clearly demonstrates a similar trend in sensitivity between bumblebee and honeybee toxicity. For example the overall toxicity of older chemical insecticides (including the carbamates, pyrethroids and organophosphates) is comparable and ranges between high to moderate except for one product (oxamyl) which was safe for bumblebees and highly toxic for honeybees. A similar trend can also be seen for the newer chemical insecticides (IGRs and neonicotinoids), the biological insecticides and the chemical fungicides, although it should be remarked that honeybees were more sensitive than bumblebees. Furthermore, an equal toxicity was observed for the different products belonging to the class of the acaricides and biological fungicides. Based on these results we argue that bumblebee toxicity, can be used as a first indication for honeybee toxicity but care is needed when different endpoints can be affected because honeybees and bumblebees are very distinct (colony live, behavior,...). Nonetheless, this would imply that a first toxicity screening can be done by using bumblebees which are easier to work with as compared to honeybees.

As mentioned above, the toxicity of the chemical insecticide class is comparable between bumblebees and honeybees. However, figure 4 shows a regression analysis with the available $\mathrm{LD}_{50 \mathrm{~s}}$ for the different PPPs belonging to the carbamates, pyrethroids, 


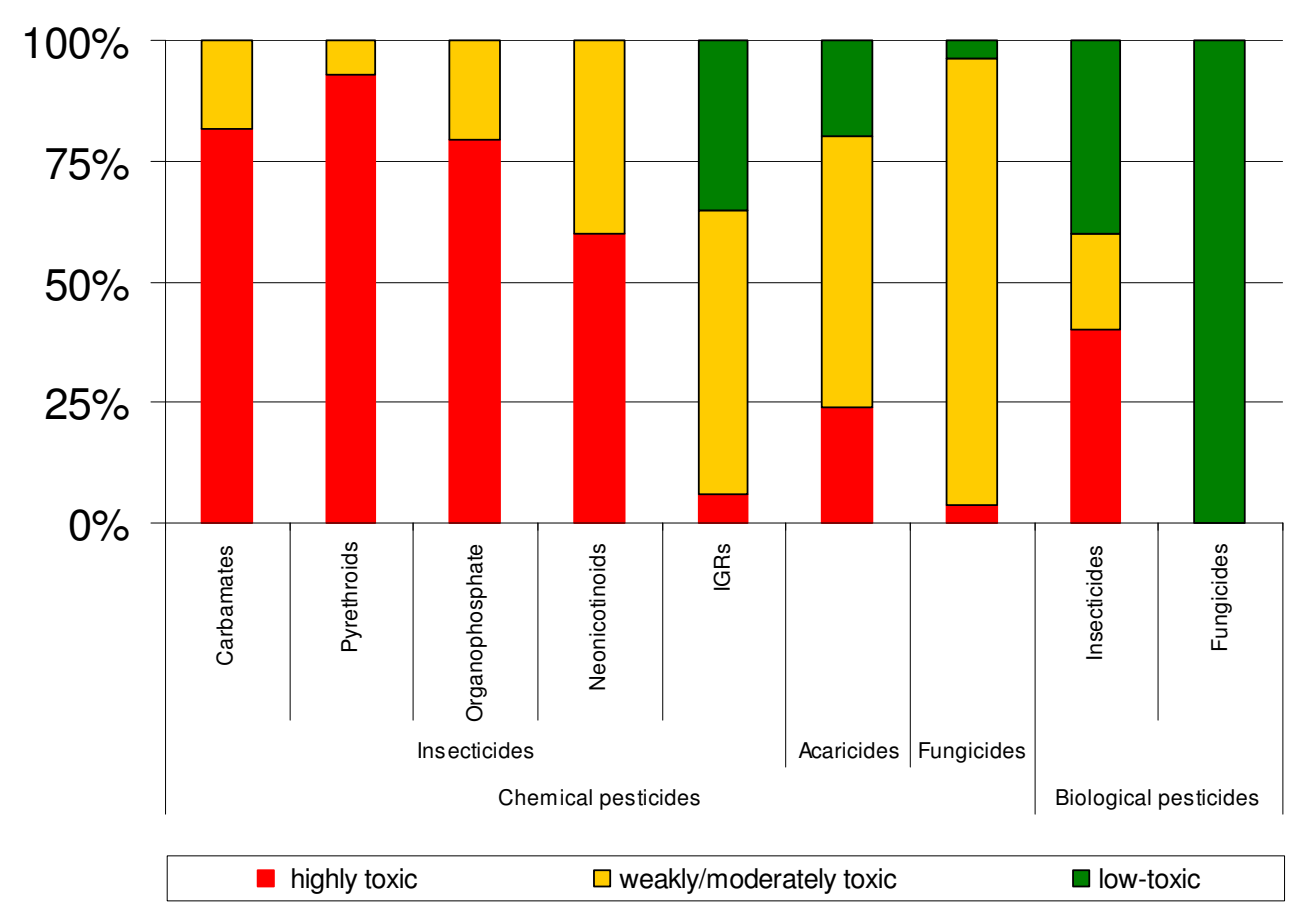

Fig. 3. Overview of the honeybee (Apis mellifera) toxicity of chemical pesticides and biological pesticides as available for bumblebees (Bombus terrestris). For each pesticide group the bars represent the percentage of compounds which are non-toxic (green), weakly/moderately toxic (yellow-orange) and toxic (red). The toxicity levels are based on the $\mathrm{LD}_{50}-48 \mathrm{~h}$ obtained after contact and oral exposure (see http://sitem.herts.ac.uk/aeru/footprint/en/index.htm). The numbers of compounds considered per group are $n=11$ for carbamates, $n=14$ for pyrethroids, $n=29$ for organophosphates, $\mathrm{n}=5$ for neonicotinoids, $\mathrm{n}=17$ for IGRs, $\mathrm{n}=5$ for biological insecticides, $\mathrm{n}=25$ for acaricides, $\mathrm{n}=62$ for chemical fungicides, and $\mathrm{n}=3$ for biological fungicides.

organophosphates, and neonicotinoids. Here the $\mathrm{LD}_{50} \mathrm{~s}$ obtained after $24 \mathrm{~h}$ exposure were used and this for 17 insecticides. When the values were expressed as $\mu \mathrm{g} / \mathrm{g}$, then these were recalculated to $\mu \mathrm{g} /$ bee based on the weights as published by Thompson (2001) (with $0.10 \mathrm{~g}$ for $A$. mellifera and $0.21 \mathrm{~g}$ for $B$. terrestris). The poor linear regression $(\mathrm{R}=0.36)$ between the toxicities of the different compounds confirms that extrapolation of toxicity data between these two pollinators is not possible. In case of the carbamates, the $\mathrm{LD}_{50} \mathrm{~S}$ of 4 compounds were obtained. Here it was shown that for $75 \%$ of the products (carbaryl, methomyl and propoxur) $B$. terrestris was up to 10 times less sensitive than honeybees. Only the $\mathrm{LD}_{50}$ for ethiofencarb was lower (more sensitive) for B. terrestris $(0.205 \mu \mathrm{g} / \mathrm{bee})$ than for $A$. mellifera $(6.85 \mu \mathrm{g} / \mathrm{bee})$. For the group of pyrethroids, $A$. mellifera was more sensitive for all 5 products. For the organophosphates, the $B$. terrestris sensitivity was variable. Out of the 7 organophosphates, there were 4 products (acephate, chlorpyrifos, demeton-S-methyl and dimethoate) for which $A$. mellifera showed a higher sensitivity than $B$. terrestris. Equal sensitivity for both pollinators was seen for oxy-demeton-methyl and paraxon while $B$. 
terrestris was 10 times more sensitive for chlorpyrifos-methyl. For the neonicotinoids $A$. mellifera was most sensitive to imidacloprid. This is in agreement with Hardstone \& Scott (2010) who concluded that A. mellifera was among the most sensitive for imidacloprid. In contrast, the sensitivity for acetamiprid was equal between both pollinators.

$$
\begin{aligned}
& y=0.3456 x+0.1235 \\
& R=0.36
\end{aligned}
$$

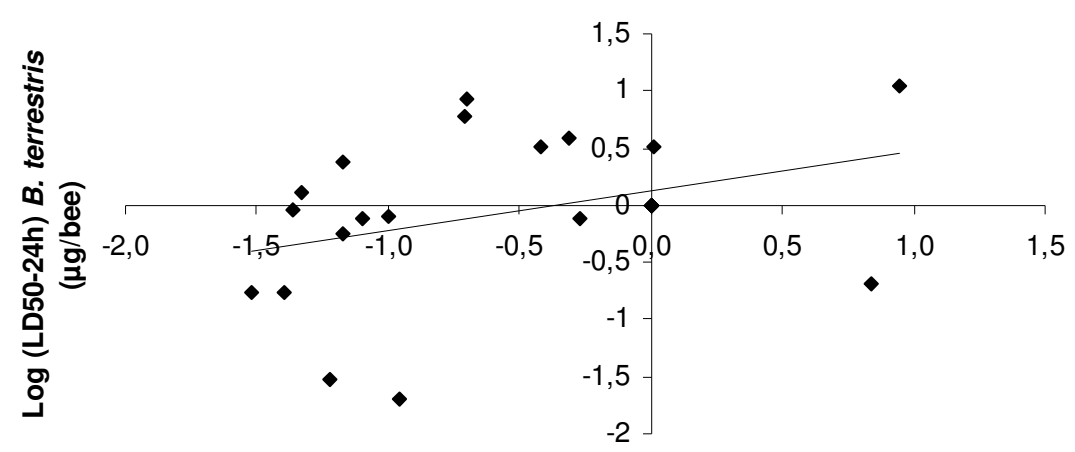

$\log (\mathrm{LD} 50-24 \mathrm{~h})$ A. mellifera $(\mu \mathrm{g} / \mathrm{bee})$

Fig. 4. Sensitivity of pesticide side-effects on bumblebees (Bombus terrestris) versus honeybees (Apis mellifera). Linear regression analysis was conducted with $\mathrm{LD}_{50}-24 \mathrm{~h}$ values after contact and oral exposure for 17 different insecticides (carbamates, pyrethroids, organophophates and neonicotinoids). Data are presented as a mean $\log \left(\mathrm{LD}_{50}-24 \mathrm{~h}\right)$ and originate from Thompson (2001), van der Steen et al. (2008) and Hardstone \& Scott (2010).

Although no linear regression could be drawn, this analysis gives a first idea of bumblebee versus honeybee sensitivity for pesticides. It needs to be remarked that the power of this analysis is limited because an $\mathrm{LD}_{50}$ was not available for each insecticide. However, based on available data for different IGRs, MACs are safe for both bumblebees and honeybees (Thompson et al., 2005; Mommaerts et al., 2006b), whereas no correlation can be found for the other two classes (CSI and JHA). Indeed, for diflubenzuron (CSIs) the $\mathrm{LD}_{50}-24 \mathrm{~h}$ on larvae showed that $B$. terrestris larvae are more sensitive than $A$. mellifera $\left(\mathrm{LD}_{50}-72 \mathrm{~h}\right.$ ) (Tasei, 2001). For the same compound also Mommaerts et al. (2006a) reported a total loss of $B$. terrestris reproduction, while Thompson et al. (2005) found only short-term effects on $A$. mellifera colonies. In contrast, for the JHA fenoxycarb, B. terrestris larvae were less susceptible (LD-24h: $>0.650 \mu \mathrm{g} /$ larvae) than $A$. mellifera larvae ( $\left.\mathrm{LD}_{50}-48 \mathrm{~h}: 0.013 \mu \mathrm{g} / \mathrm{larvae}\right)$ (Tasei, 2001). Similarly, exposure of micro-colonies to fenoxycarb at its MFRC did not result in negative effects on reproduction (Mommaerts et al., 2006b), while A. mellifera colonies started the season slower and queen mating and egg laying were affected after (oral) exposure (Thompson et al., 2005). Based on this information and in order to have a total idea of the pollinator sensitivity towards pesticides, it is recommended that future studies should also evaluate the sensitivity of pesticides on other developmental life-stages. Finally, the pesticide side-effects sensitivity between honeybees and bumblebees is not only different for chemical insecticides. Indeed, for spinosad a biological insecticide comparison showed that 
honeybees ( $\left.\mathrm{LD}_{50}-48 \mathrm{~h}: 0.16 \mu \mathrm{g} / \mathrm{bee}\right)$ were 100 times more sensitive than bumblebees $\left(\mathrm{LD}_{50^{-}}\right.$ 48h: $19.4 \mu \mathrm{g} /$ bee) (Halsall \& Grey, 1998; Aldershof, 1999).

From the above mentioned results, it is clear that risk assessment bioassays need to evaluate side-effects on species level. The reason for this difference is not only due to a difference in sensitivity, but as already argued by Thompson \& Hunt (1999) due to a difference in exposure profile. In this context they identified the following factors: namely the foraging active period, the species of crops visited, and the time of spraying (time on the day and time in the season). For example insecticides belonging to the class of the pyrethroids are applied in the early morning or late evening when they are more toxic and thus perform a higher risk for bumblebees. Similarly, risk assessment measures in honeybees are not useful for bumblebee losses which occur by pesticide applications in March-April, the moment of the year when bumblebee queens emerge and forage to find a nest place in order to start a colony (Thompson \& Hunt, 1999).

\section{Conclusions and future perspectives}

This review gives on overview of the available toxicity data of PPPs on bumblebee species used for the pollination of crops. However, when looking at the obtained data set it is clear that the information is more fragmented in comparison with honeybees. Although in the past efforts have been made to assess risks by developing a variety of methods, we propose to conduct them in a tier approach in order to assess risks in a more complete way. The different levels are: (1) laboratory tests on individual insects ("tier 1"), (2) extended laboratory tests with micro-colonies which include the evaluation of pesticides on key processes such as worker survival, reproduction and behavior ("tier 2"), and (3) semi-field and/or field tests ("tier 3"). Unfortunately, to date most studies do not include semi-field and/or field tests, while it is crucial to make a link between the observed toxicity in the laboratory and the risks under field conditions in order to fully assess the risks. For example laboratory tests ("tier 1 and 2") do not consider pesticide degradation which might occur under field conditions. In addition, the goal of each tier is to classify the PPPs according to their compatibility with bumblebees. However, this point has been overlooked as no guidelines exist for bumblebees and thus these of the IOBC are used without any validation. Proper guidelines are therefore urgently needed which resemble the consequences at colony level by, for example, taking into account the consequences of worker loss according to the size of the colony.

In this review also a wide variety of effects (lethal and sublethal effects) have been reported following pesticide exposure. For lethal effects (worker mortality) the methods used are well defined. However, comparison between pesticide toxicities remains difficult. Therefore we suggest that in the future the already available lethal toxicity tests are more standardized by using a fixed exposure time and worker age and by determining the size of the worker as the length of the bumblebee body is variable. For sublethal effects on adult workers, different endpoints have already been evaluated such as worker life-span, worker biomass, start of oviposition, and this with adequately developed methods. In contrast, sublethal effects on the bumblebee brood have been assessed but these bioassays need to be further improved. Indeed, in honeybees a brood test was recently developed where brood is kept in individual cells without the presence of adults. For bumblebees, the development of such method would benefit from the existing one where side-effects are evaluated by collection of the larvae removed from their cocoon. Moreover, such new test would allow to work 


\begin{tabular}{|c|c|c|c|c|c|c|c|c|c|c|}
\hline ્ֻّ & & & 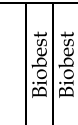 & 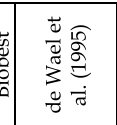 & 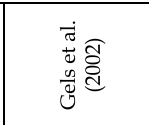 & 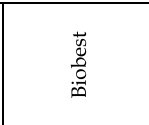 & 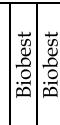 & 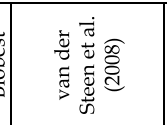 & 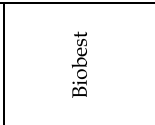 & 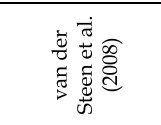 \\
\hline 芯 & & & $\infty$ & & & $\infty$ & 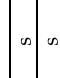 & & $\infty$ & \\
\hline 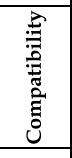 & & & 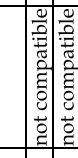 & & & 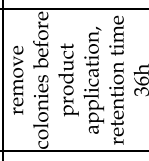 & 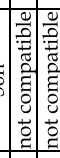 & & 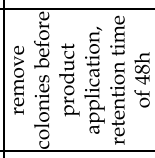 & \\
\hline \multirow{4}{*}{ 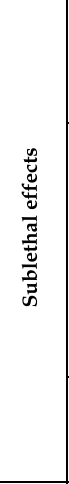 } & 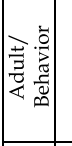 & & & & 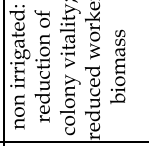 & & & & & \\
\hline & 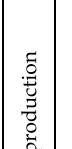 & 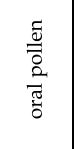 & & & & & & & & \\
\hline & $\approx$ & 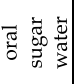 & & & & & & & & \\
\hline & & 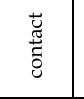 & & & 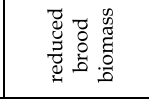 & & & & & \\
\hline \multirow{3}{*}{ 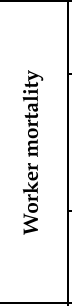 } & & 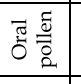 & & & & & & & & \\
\hline & & 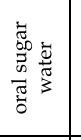 & & 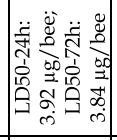 & & & & 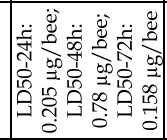 & & 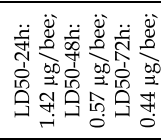 \\
\hline & & 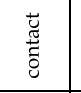 & & & & & & & & \\
\hline 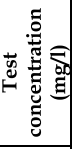 & & & $\cong \simeq$ & 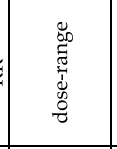 & & $\stackrel{ }{\simeq}$ & $\cong$ & & 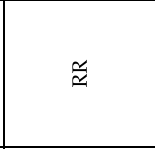 & \\
\hline 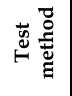 & & & ¿ $\bar{z}$ & $\bar{z}$ & 률 & $\bar{z}$ & $\overline{\mathrm{z}} \mathrm{z}$ & & z & \\
\hline 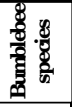 & & & $\bar{z}$ & $\bar{z}$ & 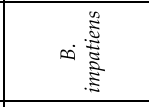 & $\bar{z}$ & $\bar{z} \mid \bar{z}$ & & $\bar{z}$ & 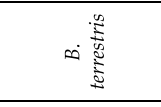 \\
\hline 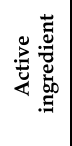 & & 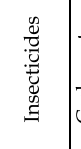 & 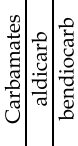 & 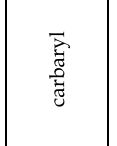 & & & 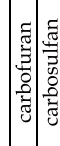 & 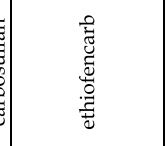 & & 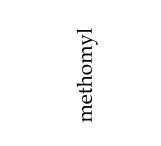 \\
\hline
\end{tabular}

Table 1. Continued 


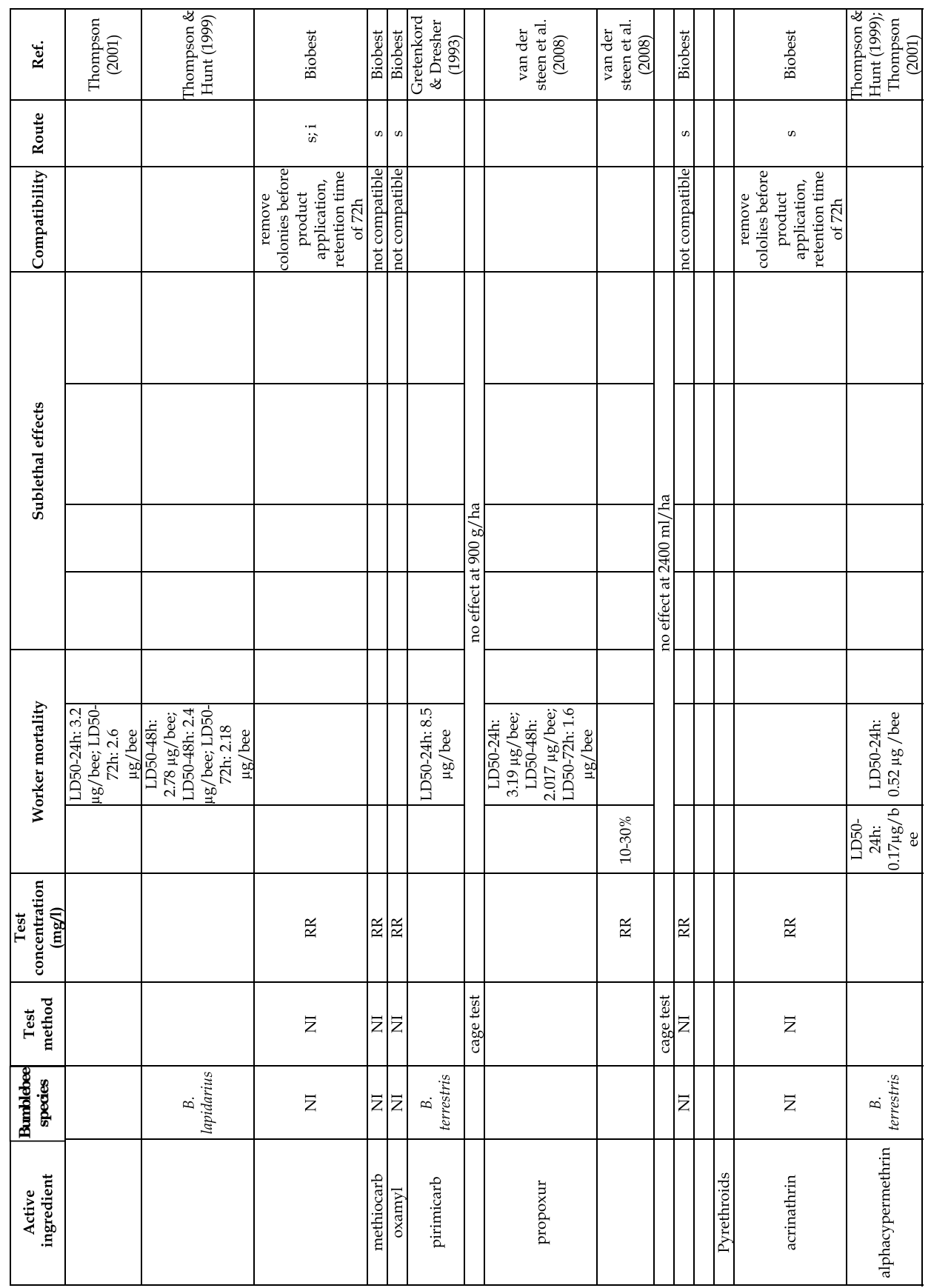

Table 1. Continued 


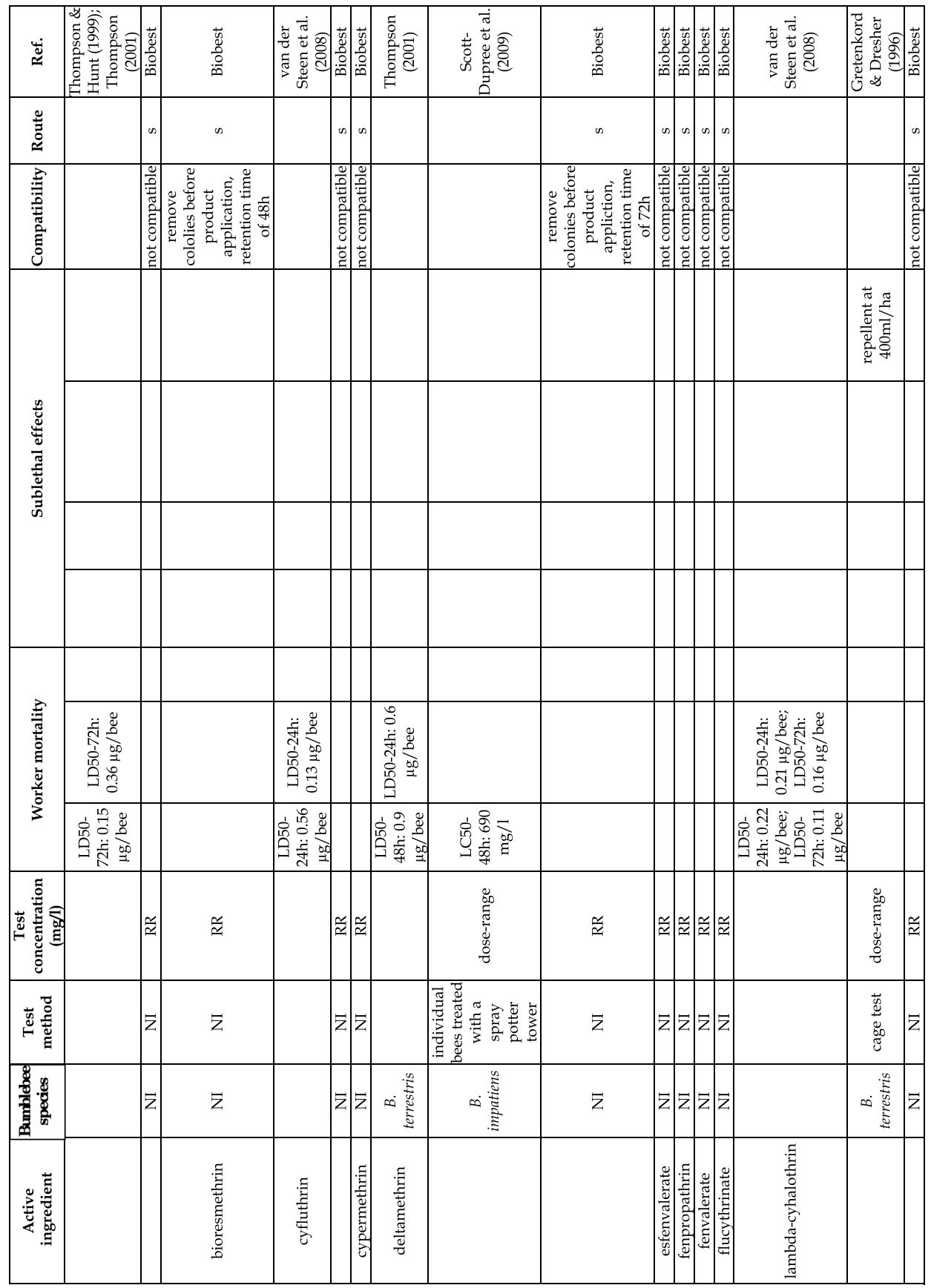

Table 1. Continued 


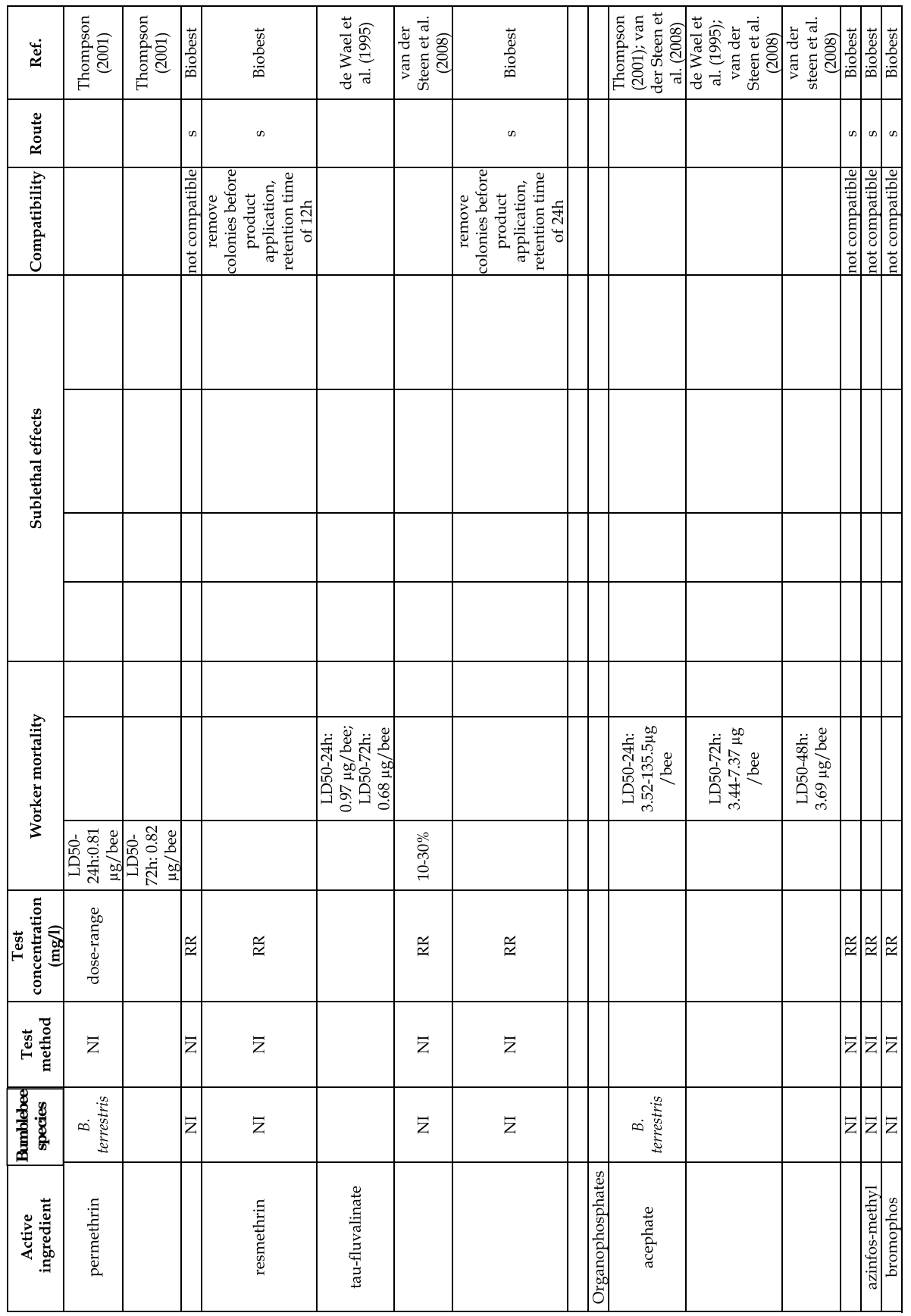

Table 1. Continued 


\begin{tabular}{|c|c|c|c|c|c|c|c|c|c|c|c|c|}
\hline 岕 & 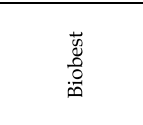 & 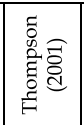 & 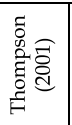 & $\mid$ & 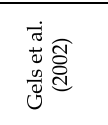 & 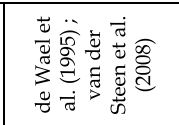 & 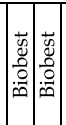 & in & 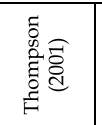 & 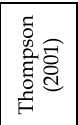 & 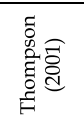 & 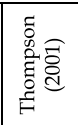 \\
\hline 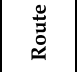 & $\infty$ & & & is & & & $\infty \begin{array}{lll}\infty & \infty\end{array}$ & & & & & \\
\hline 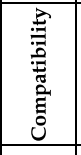 & 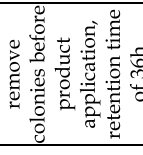 & & & 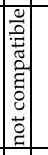 & & & 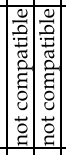 & & & & & \\
\hline \multirow{4}{*}{ 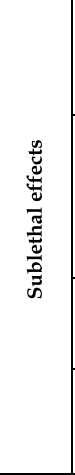 } & & & & & 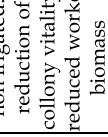 & & & & & & & \\
\hline & & & & & & & & & 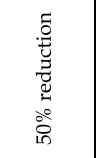 & & & 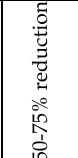 \\
\hline & & & & & & & & & 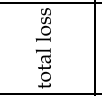 & & & 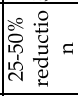 \\
\hline & & & & & 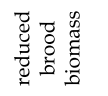 & & & & 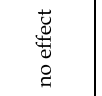 & & & 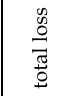 \\
\hline & & & & & & & & & 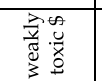 & & & 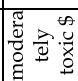 \\
\hline \multirow[t]{2}{*}{ 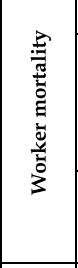 } & & & & & & 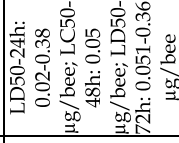 & & & & & & \\
\hline & & 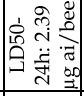 & 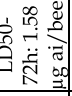 & & & 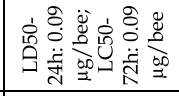 & & 列 & 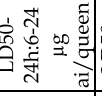 & 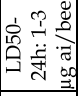 & 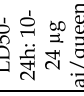 & 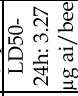 \\
\hline 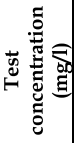 & 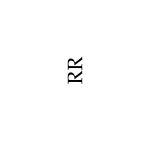 & & & 緗 & & & $\cong$ & & & & & \\
\hline 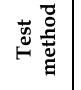 & $\bar{z}$ & & & $\bar{z}$ & 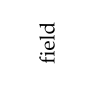 & & $\vec{z} \bar{z}$ & & & & & \\
\hline 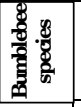 & $\bar{z}$ & $\infty$ & & $\bar{z}$ & 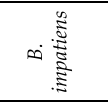 & & $\bar{z} \mathbf{z}$ & 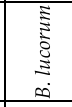 & & 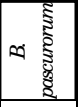 & & $\infty$ 宽 \\
\hline 咅 & 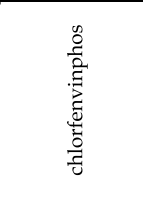 & 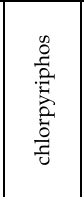 & & & & 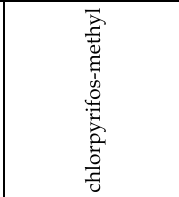 & 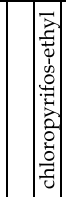 & 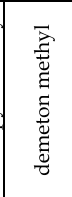 & & & & 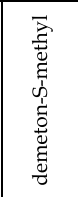 \\
\hline
\end{tabular}

Table 1. Continued 


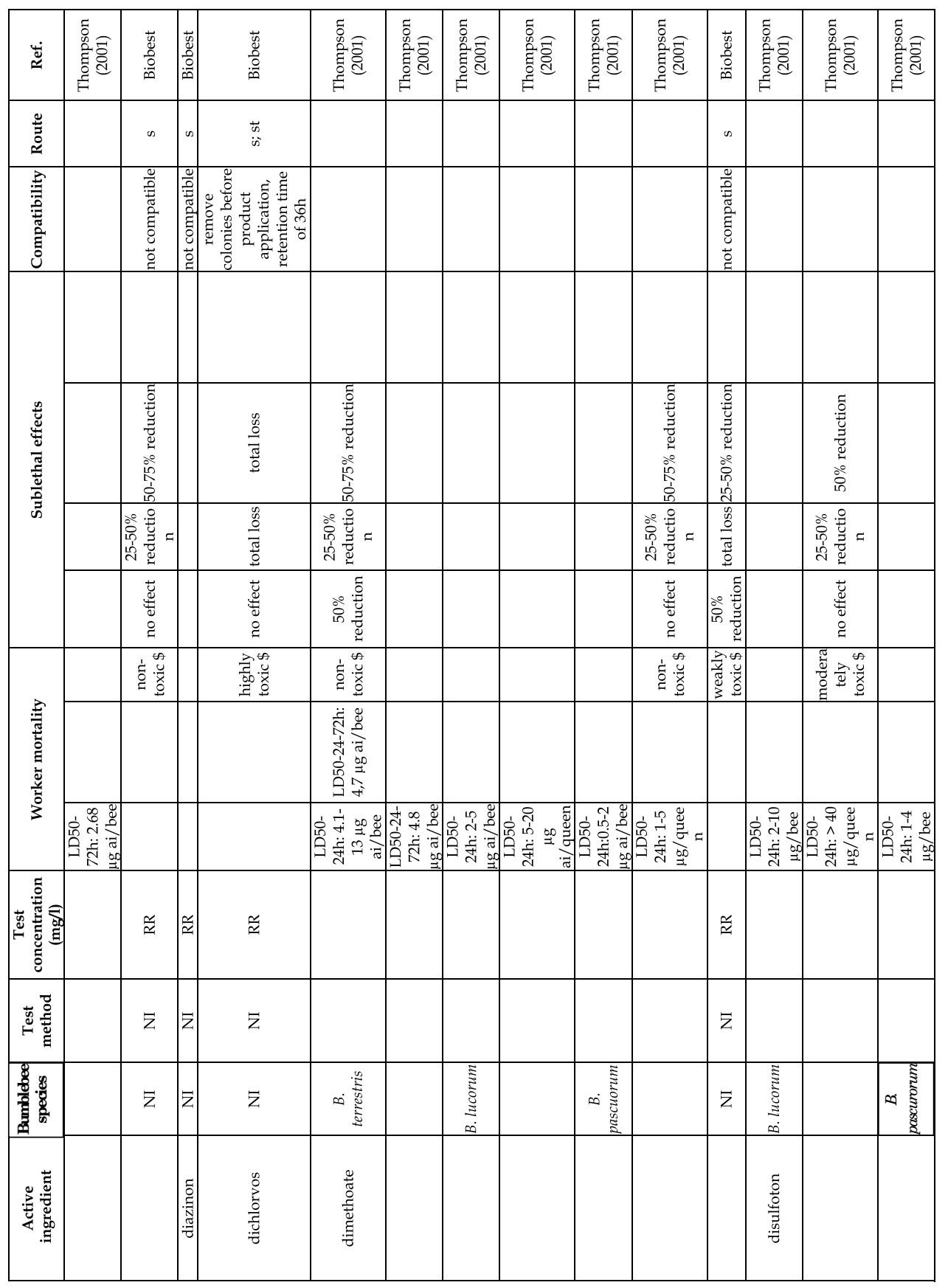

Table 1. Continued 


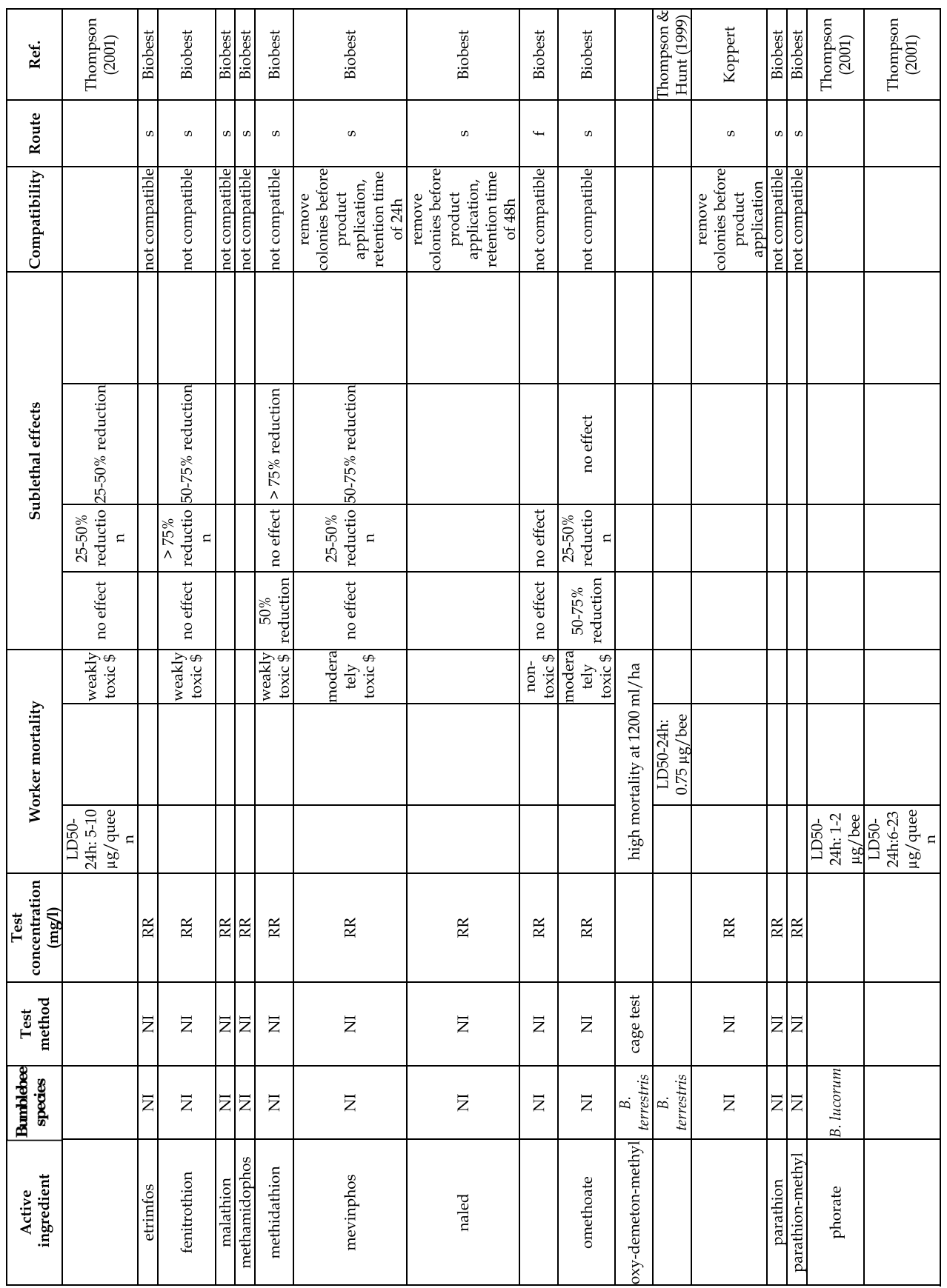

Table 1. Continued 


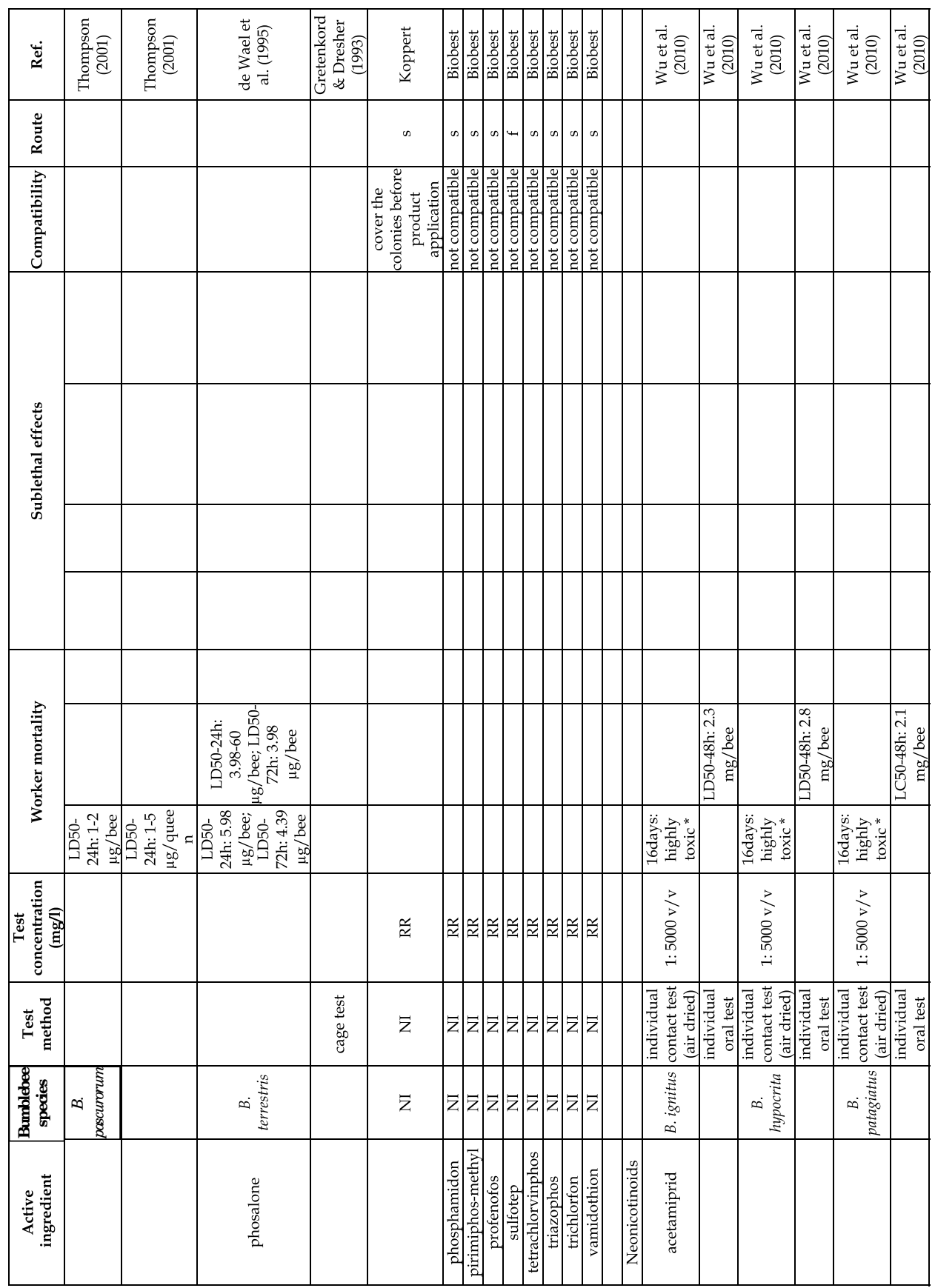

Table 1. Continued 


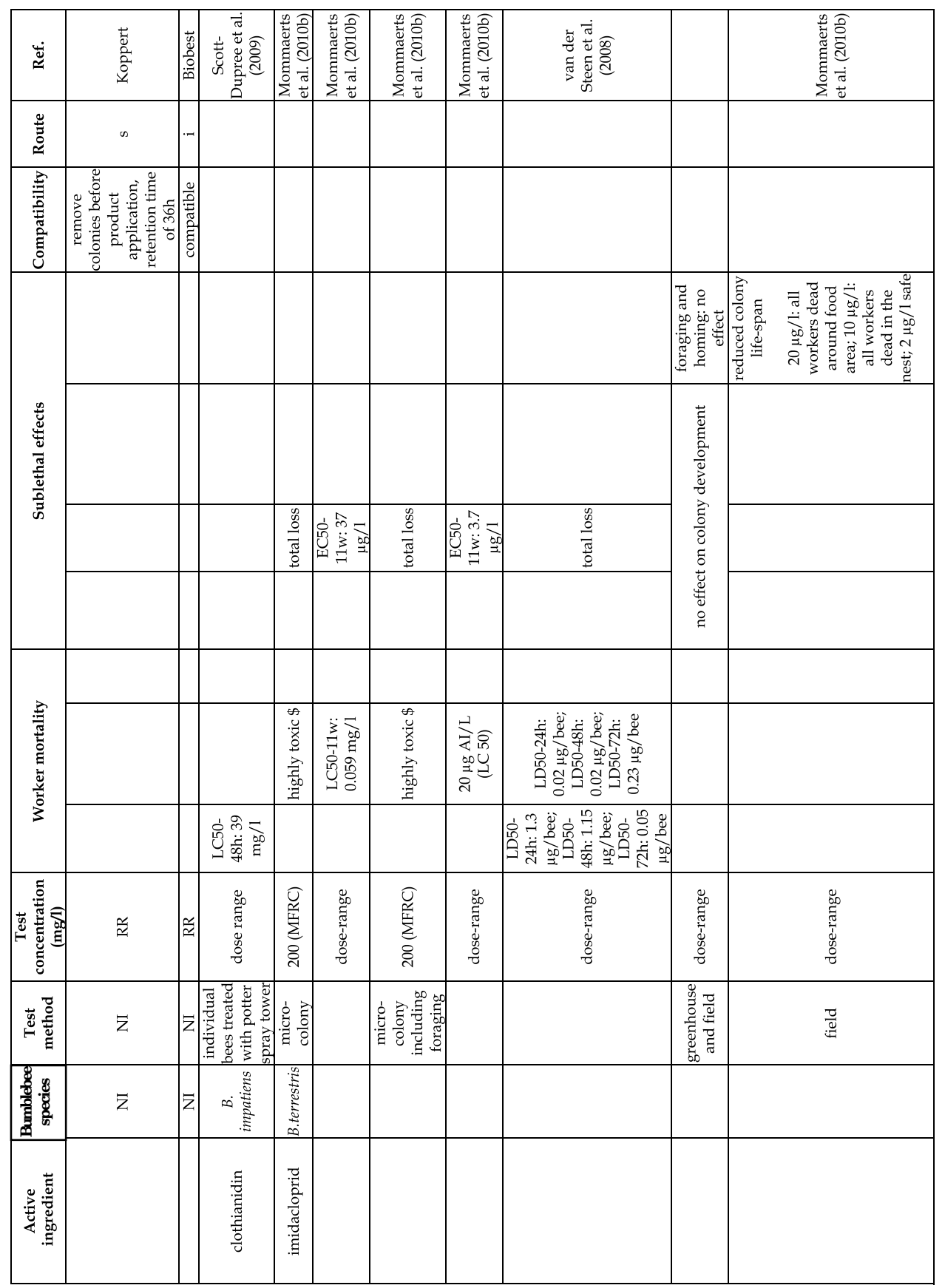

Table 1. Continued 


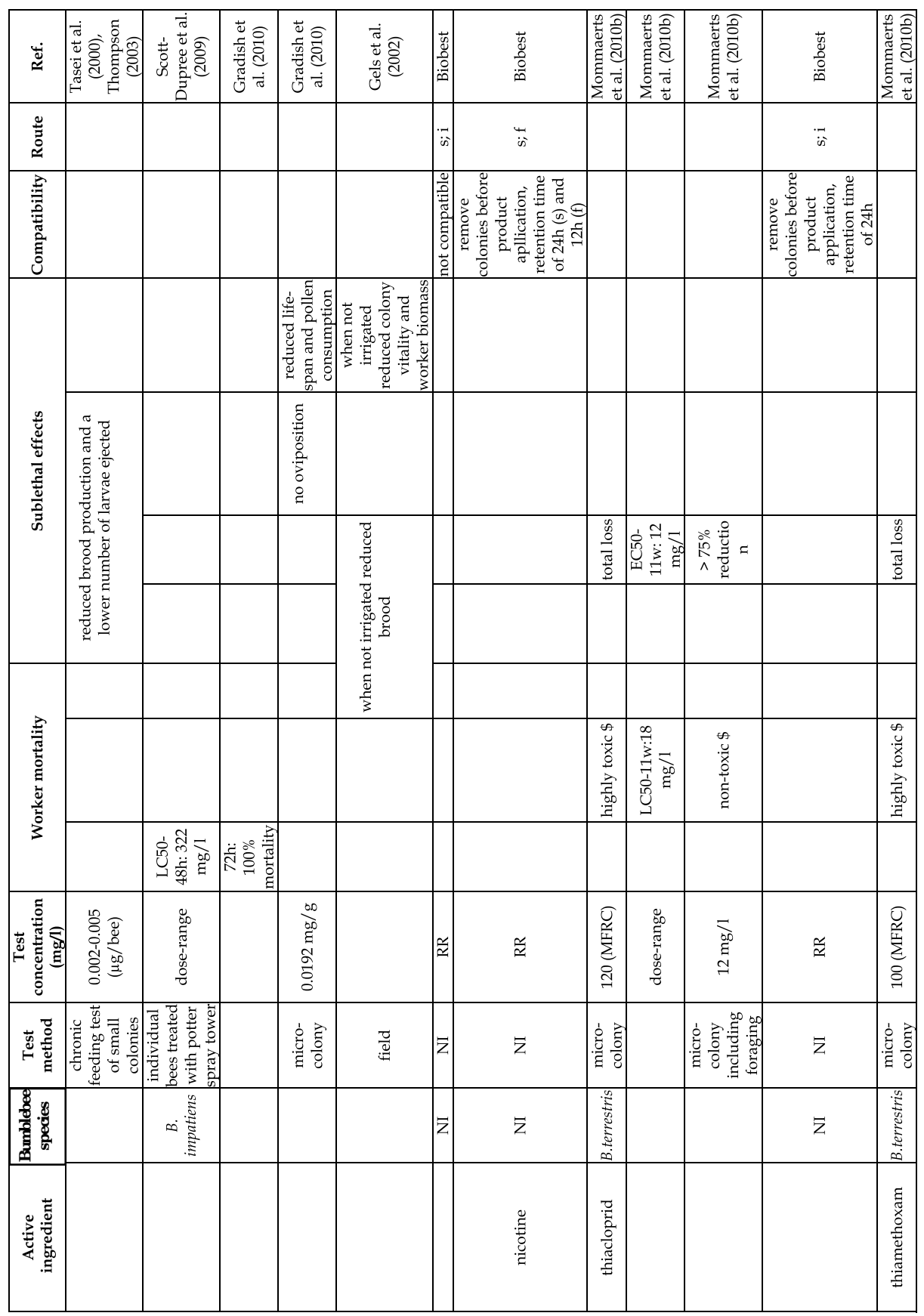

Table 1. Continued 


\begin{tabular}{|c|c|c|c|c|c|c|c|c|c|c|c|c|c|c|c|c|}
\hline 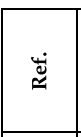 & 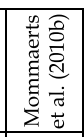 & 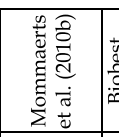 & 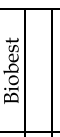 & & 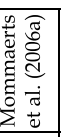 & 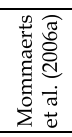 & 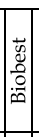 & 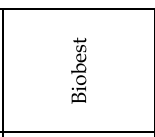 & 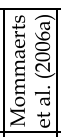 & 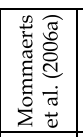 & 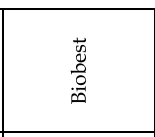 & 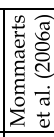 & 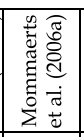 & 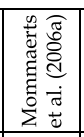 & : & 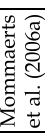 \\
\hline 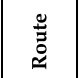 & & & $\infty$ & & & & $\infty$ & $\infty$ & & & $\infty$ & & & & $\infty$ & \\
\hline 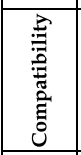 & & & 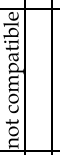 & & & & & 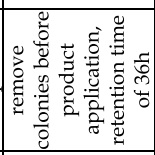 & & & 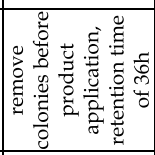 & & & & 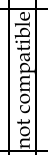 & \\
\hline \multirow{4}{*}{ 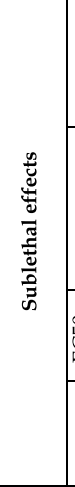 } & & & & & & & & & & & & & 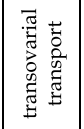 & 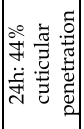 & & \\
\hline & & & & & 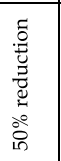 & 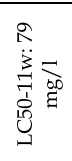 & & & 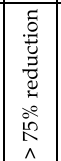 & 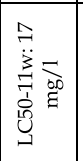 & & 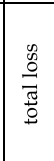 & 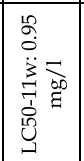 & & & 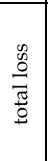 \\
\hline & 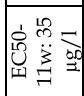 & 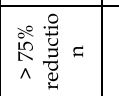 & & & 象 & 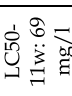 & & & 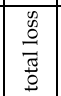 & 要 & & 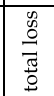 & 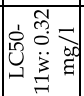 & & & $\begin{array}{l}\vec{u} \\
\text { 节 } \\
\text { g }\end{array}$ \\
\hline & & & & & 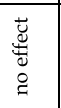 & 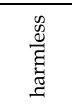 & & & 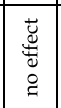 & 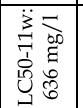 & & 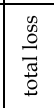 & 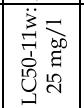 & & & 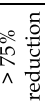 \\
\hline \multirow{3}{*}{ 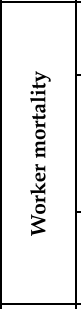 } & & & & & 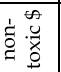 & & & & 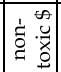 & & & 它 & & & & 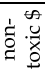 \\
\hline & 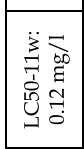 & 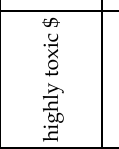 & & & 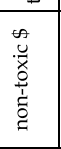 & & & & 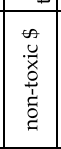 & & & 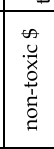 & & & & 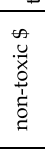 \\
\hline & & & & & 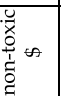 & & & & 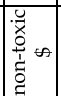 & & & 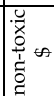 & & & & مه \\
\hline 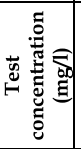 & 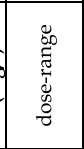 & $\begin{array}{l}\overrightarrow{b 0} \\
\stackrel{5}{a} \\
\stackrel{0}{0}\end{array}$ & $\stackrel{\cong}{\approx}$ & & 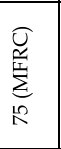 & 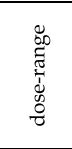 & $\approx$ & $\stackrel{2}{2}$ & 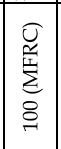 & 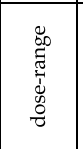 & $\stackrel{\approx}{\approx}$ & 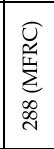 & 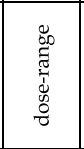 & 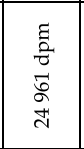 & $\approx$ & 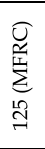 \\
\hline 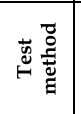 & & 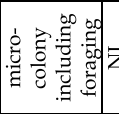 & & & 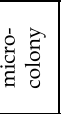 & & $\bar{z}$ & $\bar{z}$ & 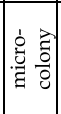 & & $\bar{z}$ & 递 & & 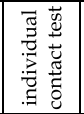 & z. & 흘 \\
\hline 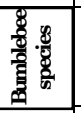 & & & $\bar{z}$ & & 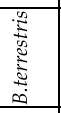 & & $\bar{z}$ & $\bar{z}$ & 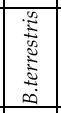 & & $\bar{z}$ & 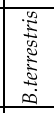 & & & $\bar{z}$ & 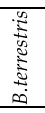 \\
\hline 至 & & & 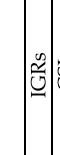 & & 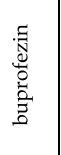 & & & 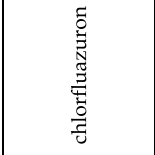 & 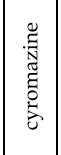 & & & 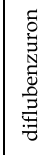 & & & & 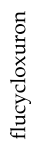 \\
\hline
\end{tabular}

Table 1. Continued 


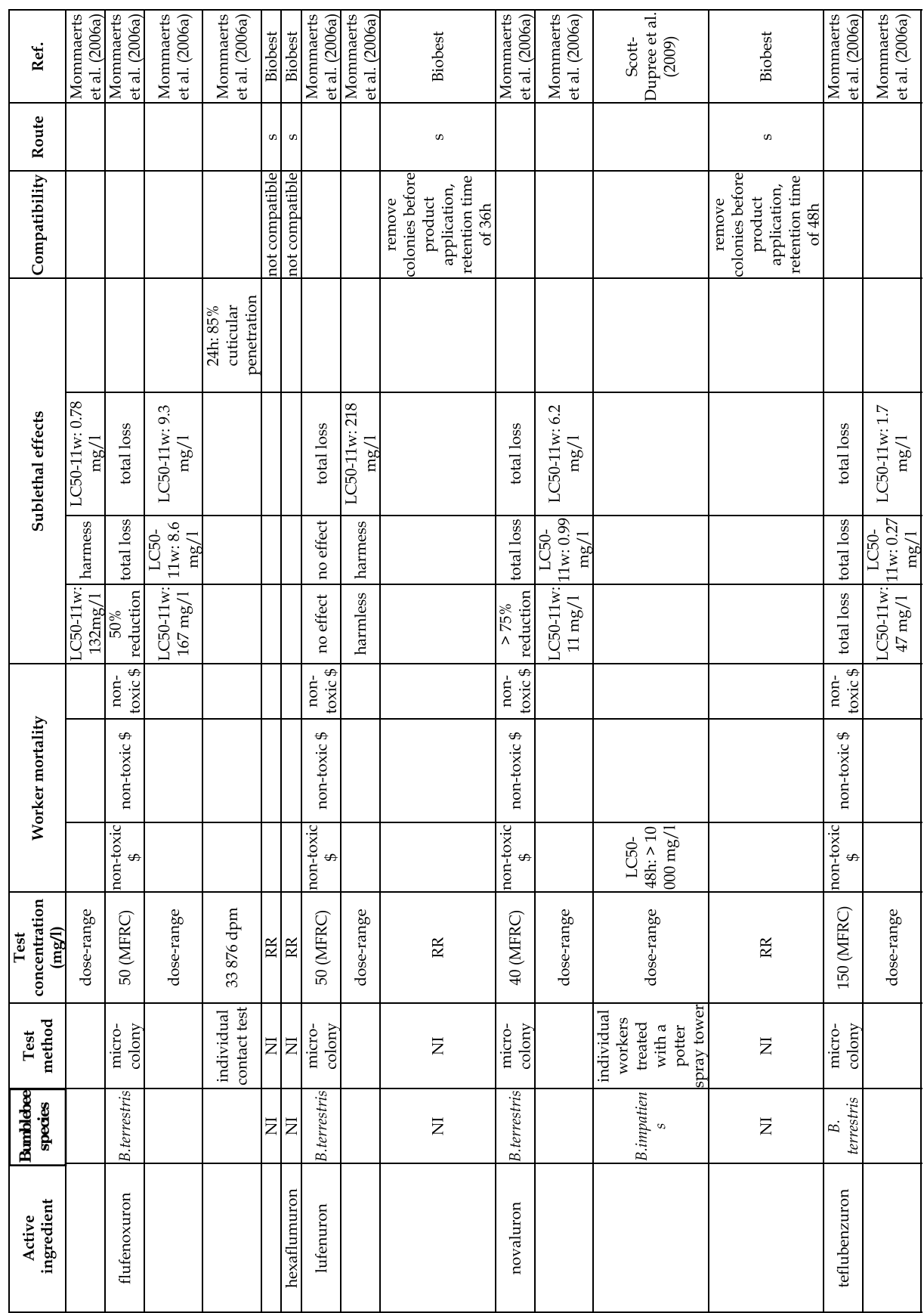

Table 1. Continued 


\begin{tabular}{|c|c|c|c|c|c|c|c|c|c|c|c|c|c|c|}
\hline ๕ّ & 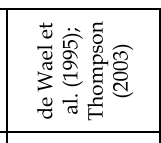 & 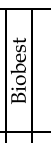 & 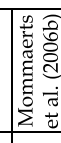 & & 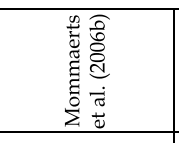 & 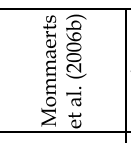 & 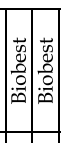 & 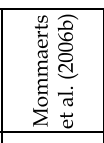 & 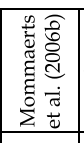 & 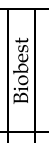 & 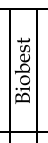 & 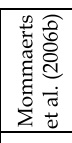 & 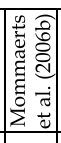 & 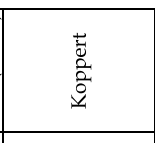 \\
\hline $\begin{array}{l}\stackrel{\Xi}{\Xi} \\
\cong\end{array}$ & & $\infty$ & & $\infty$ & & & $\infty$ & & & $\infty$ & $\infty$ & & & $\infty$ \\
\hline 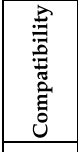 & & 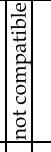 & & $\mid$ & & & 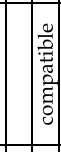 & & & 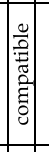 & 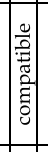 & & & 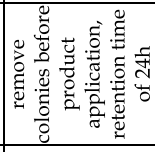 \\
\hline \multirow{4}{*}{ 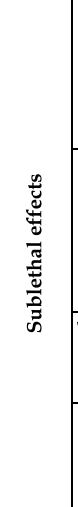 } & 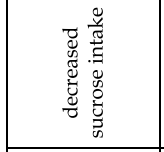 & & & & & 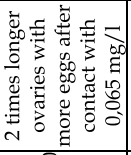 & & & 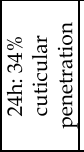 & & & 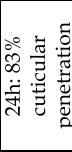 & & \\
\hline & & & 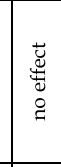 & & 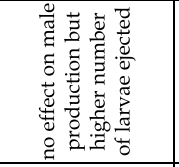 & 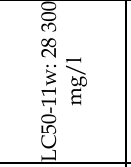 & & 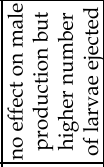 & & & & & 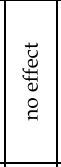 & \\
\hline & 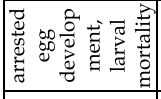 & & 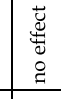 & & 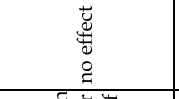 & & & 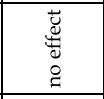 & & & & & 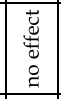 & \\
\hline & & & 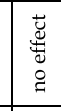 & & 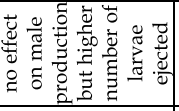 & 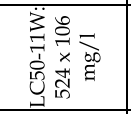 & & 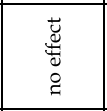 & & & & & 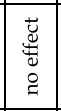 & \\
\hline \multirow{3}{*}{ 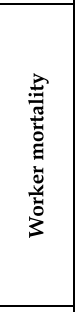 } & & & 方站 & & 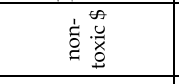 & & & 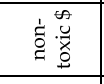 & & & & & 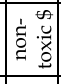 & \\
\hline & & & 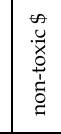 & & 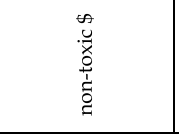 & & & 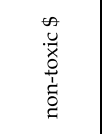 & & & & & 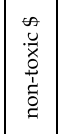 & \\
\hline & & & 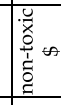 & & 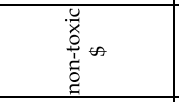 & & & 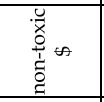 & & & & & 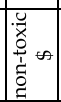 & \\
\hline 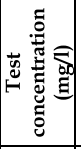 & $\begin{array}{l}\sum_{00}^{\circ} \\
\substack{00 \\
0 \\
0 \\
0}\end{array}$ & $\approx$ & 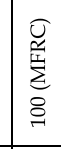 & $\approx$ & 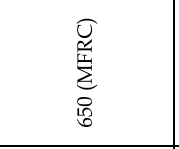 & 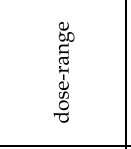 & 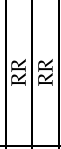 & 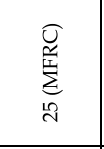 & 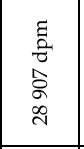 & $\widetilde{\sim}$ & 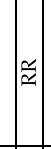 & 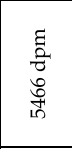 & 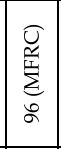 & $\cong$ \\
\hline 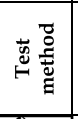 & 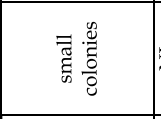 & z & 㝴 & & 总 & & |z & 爮 & 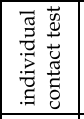 & $\bar{z}$ & z & 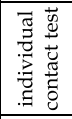 & 它 & z \\
\hline 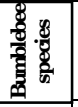 & & $\bar{z}$ & $\infty$ & & 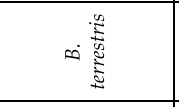 & & $\bar{z} \mid \bar{z}$ & $\infty$ & & $\bar{z}$ & z & 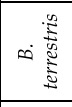 & $\infty$ & $\bar{z}$ \\
\hline 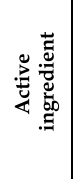 & & 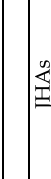 & 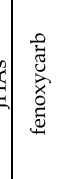 & & 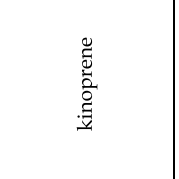 & & 离 & 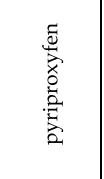 & & & 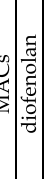 & 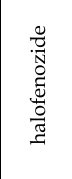 & 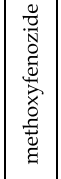 & \\
\hline
\end{tabular}

Table 1. Continued 


\begin{tabular}{|c|c|c|c|c|c|c|c|c|c|c|c|c|c|c|}
\hline$\dddot{\breve{v}}$ & 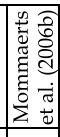 & & & 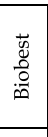 & 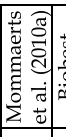 & 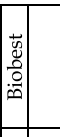 & 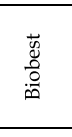 & 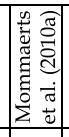 & 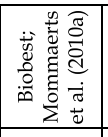 & 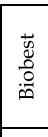 & 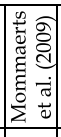 & 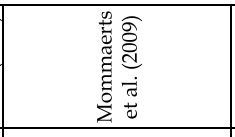 & 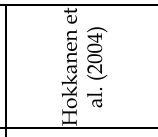 & 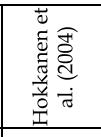 \\
\hline $\begin{array}{l}\stackrel{\Xi}{\Xi} \\
\approx \\
\approx\end{array}$ & & $\infty$ & & $\infty$ & & $\infty$ & $\infty$ & & is & $\infty$ & & & & \\
\hline 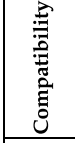 & & 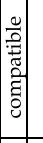 & & 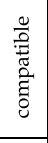 & & 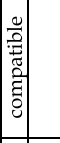 & 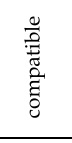 & & 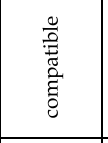 & 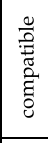 & & & & \\
\hline \multirow[t]{3}{*}{ 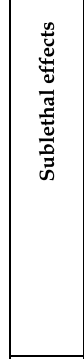 } & 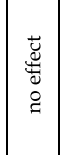 & & & & 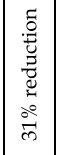 & & & 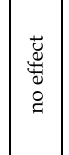 & 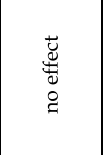 & & 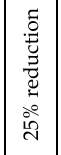 & & & \\
\hline & 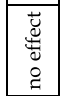 & & & & 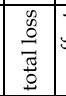 & 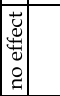 & 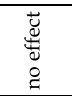 & 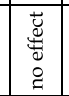 & 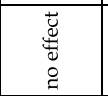 & & 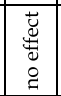 & 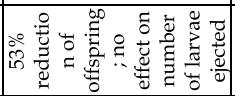 & & \\
\hline & 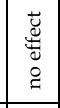 & & & & 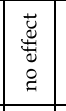 & & & 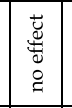 & 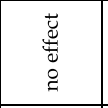 & & 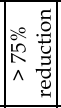 & & & \\
\hline \multirow{3}{*}{ 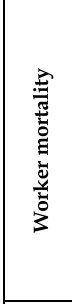 } & 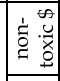 & & & & 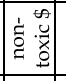 & & & 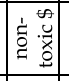 & 咅: & & 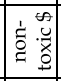 & & & \\
\hline & 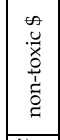 & & & & 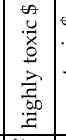 & $\mid$ & 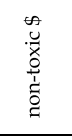 & 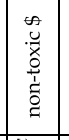 & 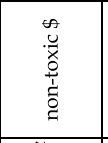 & & 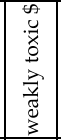 & 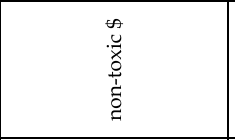 & & \\
\hline & 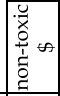 & & & & 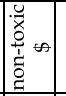 & & & 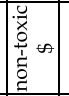 & 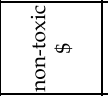 & & 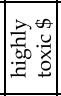 & & ఫें & 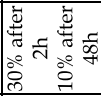 \\
\hline 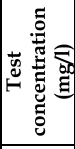 & 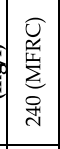 & & & & 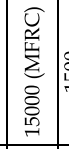 & . & & 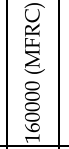 & & & 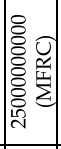 & & 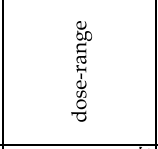 & 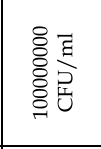 \\
\hline 索总 & 它 & & & & 送: & : & 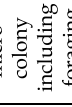 & : & 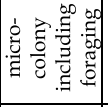 & & : & 它客: & 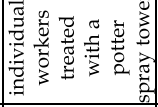 & 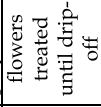 \\
\hline 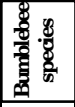 & $\infty)$ & & & & 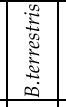 & & & 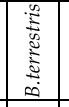 & & & 焉 & & 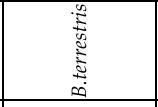 & \\
\hline 焉 & 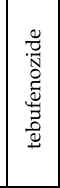 & & 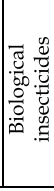 & 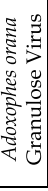 & 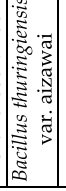 & & 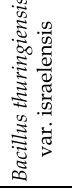 & 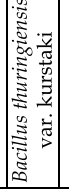 & & 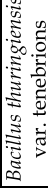 & 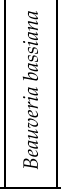 & & & \\
\hline
\end{tabular}

Table 1. Continued 


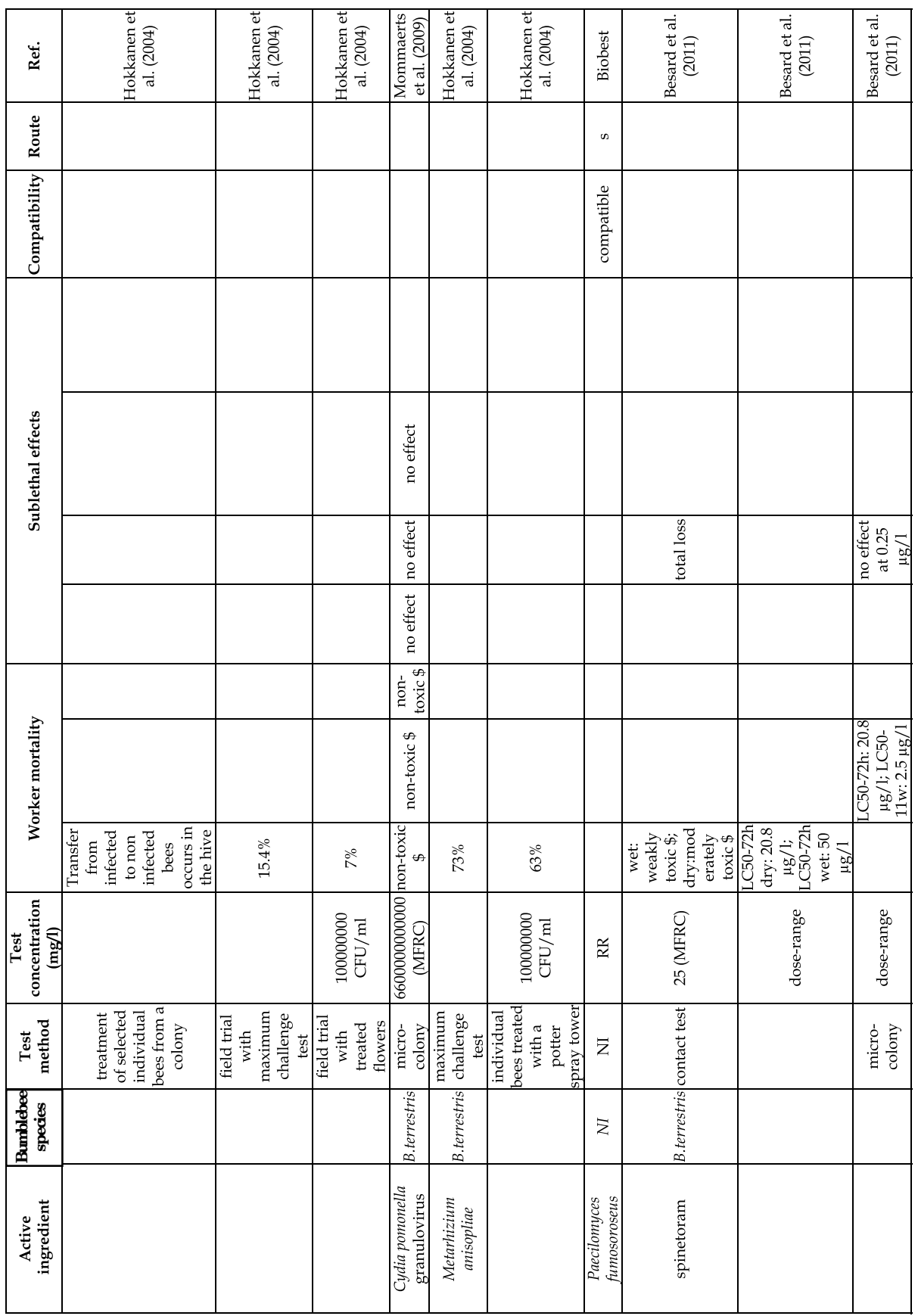

Table 1. Continued 


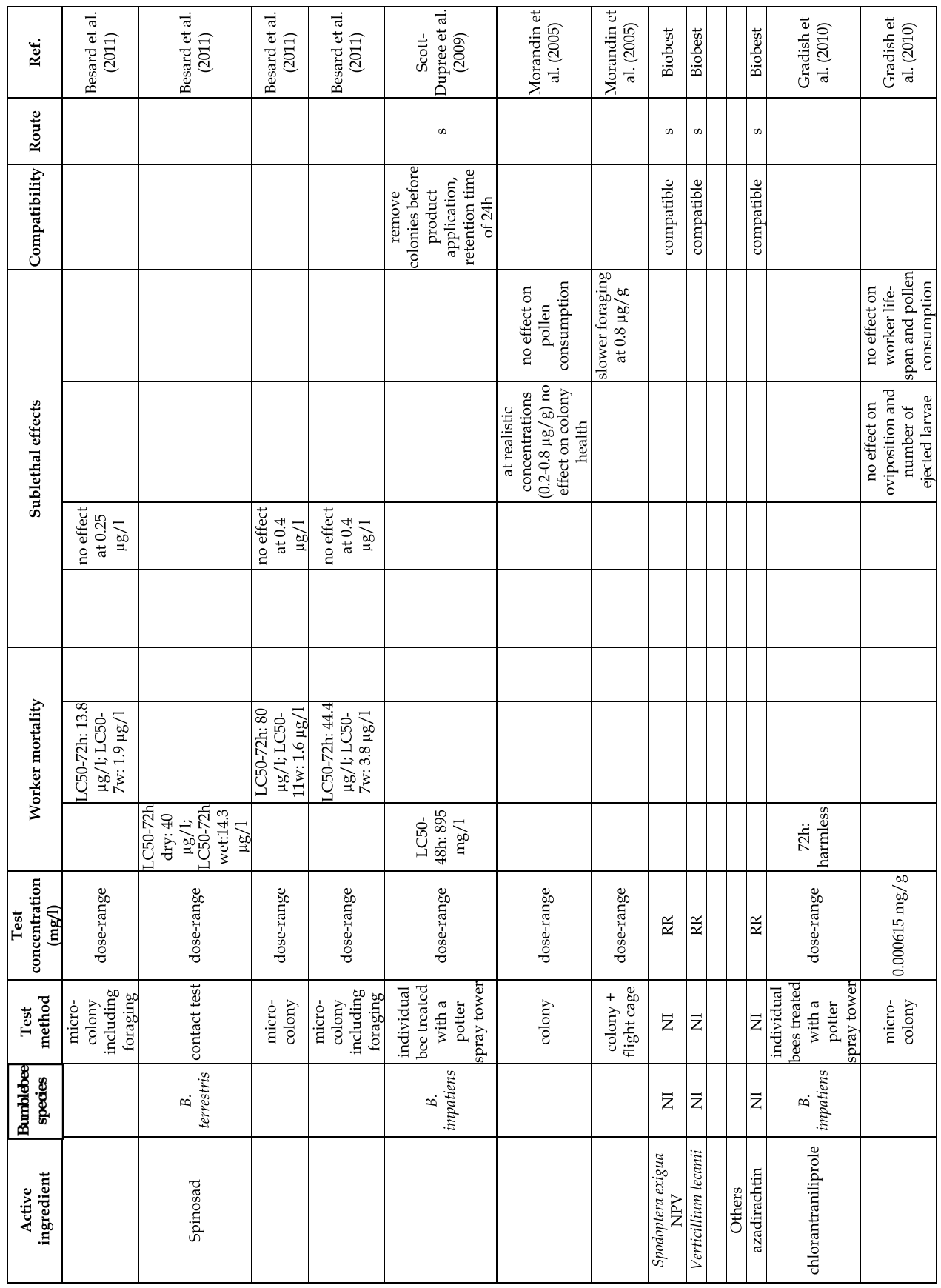

Table 1. Continued 


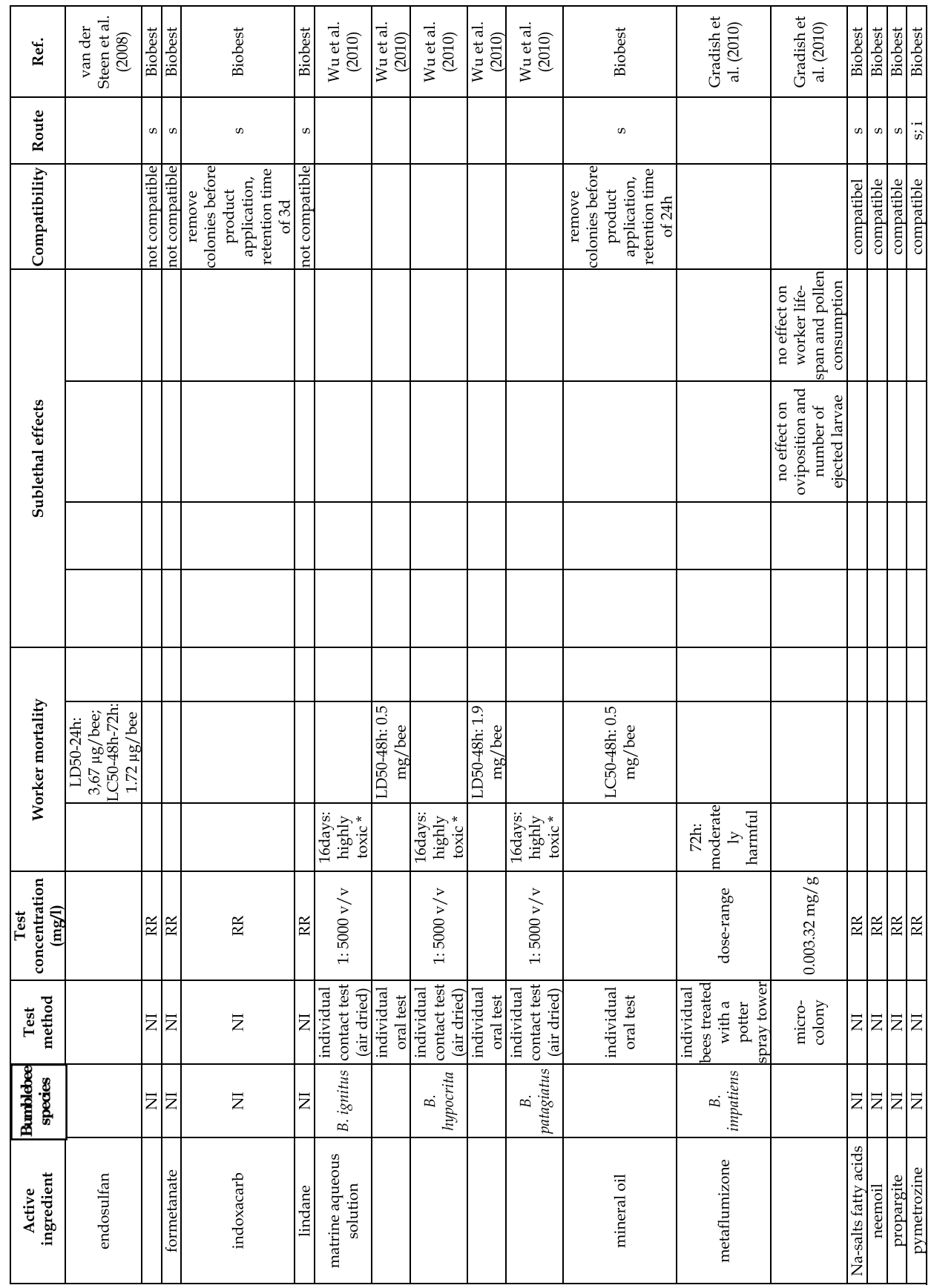

Table 1. Continued 


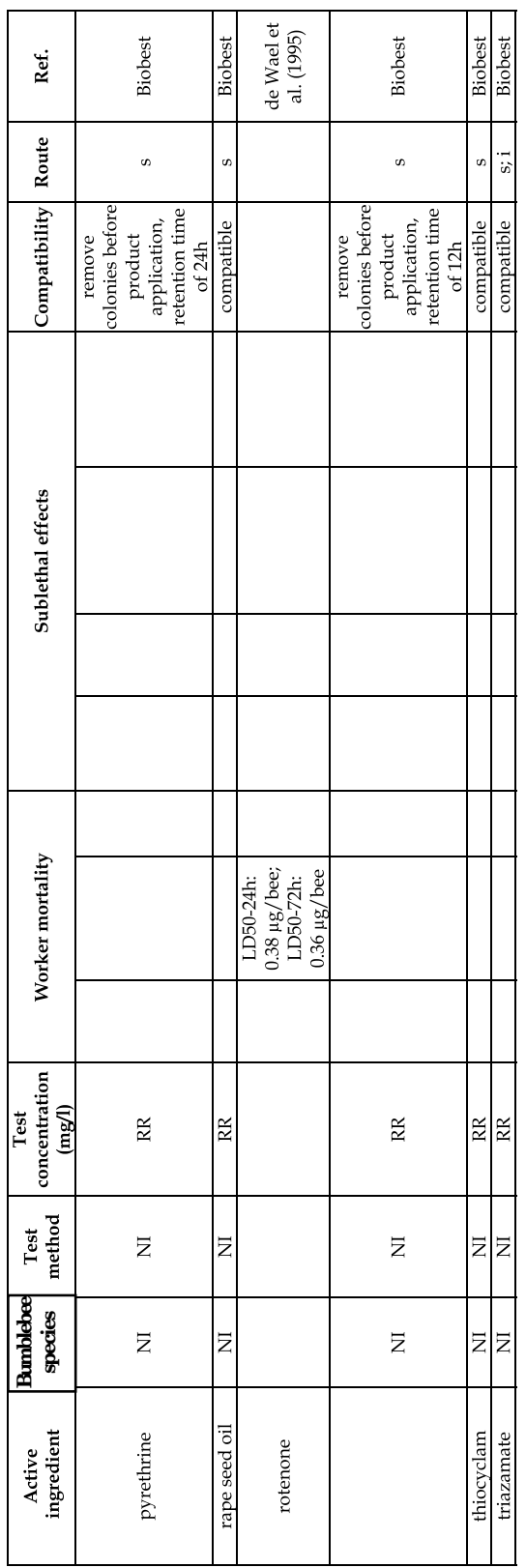

Table 1. Overview of the toxicity of insecticides towards Bombus species, (NI: no information; RR: recommended rate; \$: toxicity according to the IOBC classification for extended laboratory tests; * toxicity according to the IOBC classification for laboratory studies; £: compatibility according to the side-effect list; Route (s=spraying, st=space treatment, $\mathrm{i}=$ irrigation, $\mathrm{d}=$ dusting, $\mathrm{f}=$ fumigation ) 


\begin{tabular}{|c|c|c|c|c|c|c|c|c|c|c|c|c|c|c|c|c|}
\hline$\dot{\ddot{̉}}$ & & & 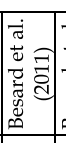 & 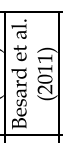 & 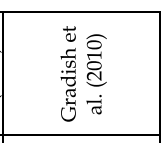 & 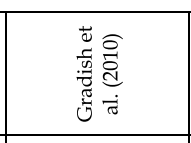 & 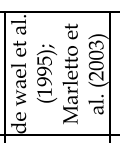 & 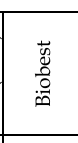 & 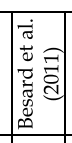 & ât & 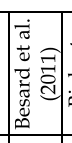 & 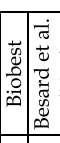 & : & 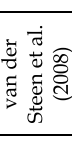 & 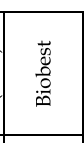 & \\
\hline : & & & & & & & & $\infty$ & & $\infty$ & & $\infty$ & & & $\infty$ & \\
\hline 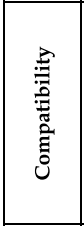 & & & & & & & & 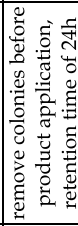 & & 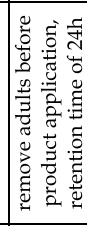 & & 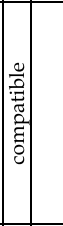 & & & 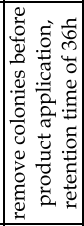 & |̇: \\
\hline \multirow{4}{*}{ 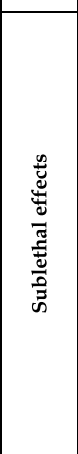 } & 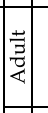 & & & & & 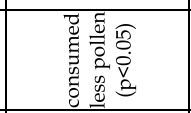 & & & & & & & & & & \\
\hline & $\mid$ & 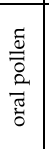 & 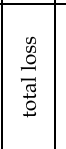 & & & 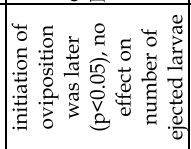 & & & 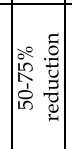 & & 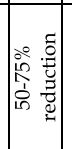 & & | & & & \\
\hline & 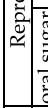 & 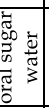 & & & & & & & 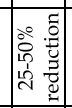 & & 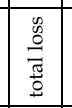 & & |: & & & \\
\hline & & 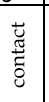 & 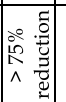 & & & & & & 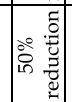 & & 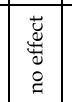 & & 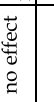 & & & \\
\hline \multirow{3}{*}{ 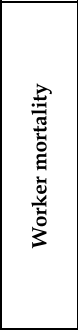 } & & 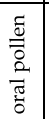 & 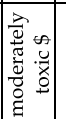 & & & 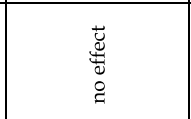 & \multirow{2}{*}{ 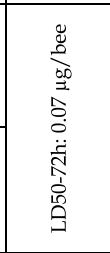 } & & 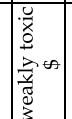 & & 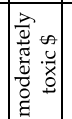 & & : & & & \\
\hline & & 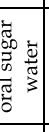 & 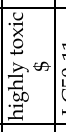 & 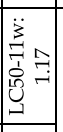 & \multirow{2}{*}{ 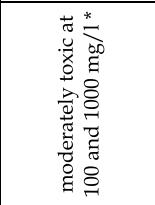 } & & & & 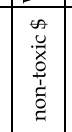 & & 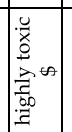 & & 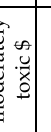 & 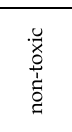 & & \\
\hline & & 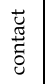 & 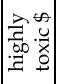 & & & & 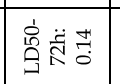 & & 它 & & 竞 & & 告 & 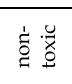 & & \\
\hline 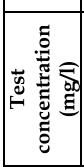 & & & 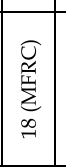 & 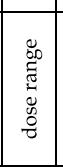 & $\begin{array}{l}8 \\
8 \\
\stackrel{1}{0} \\
\stackrel{0}{0} \\
0\end{array}$ & 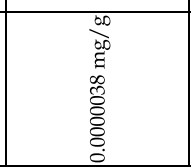 & & $\widetilde{\approx}$ & 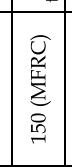 & $\cong$ & 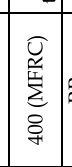 & 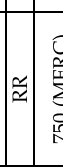 & 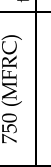 & & $\stackrel{\cong}{\simeq}$ & \\
\hline 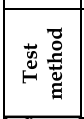 & & & 㝴 & & 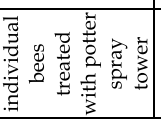 & 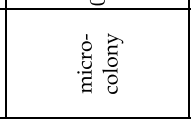 & & $\bar{z}$ & 总 & $\Sigma$ & 它 & $\bar{z}$ & : & & $\bar{z}$ & \\
\hline 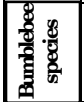 & & & $\infty$ & & का & & & $\bar{z}$ & 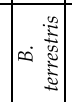 & z & 告 & $\bar{z}$ & : & & $\bar{z}$ & \\
\hline 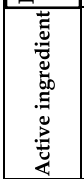 & & 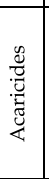 & 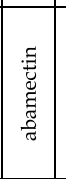 & & & & & & 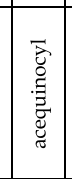 & & है & & 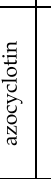 & & & \\
\hline
\end{tabular}

Table 2. Continued 


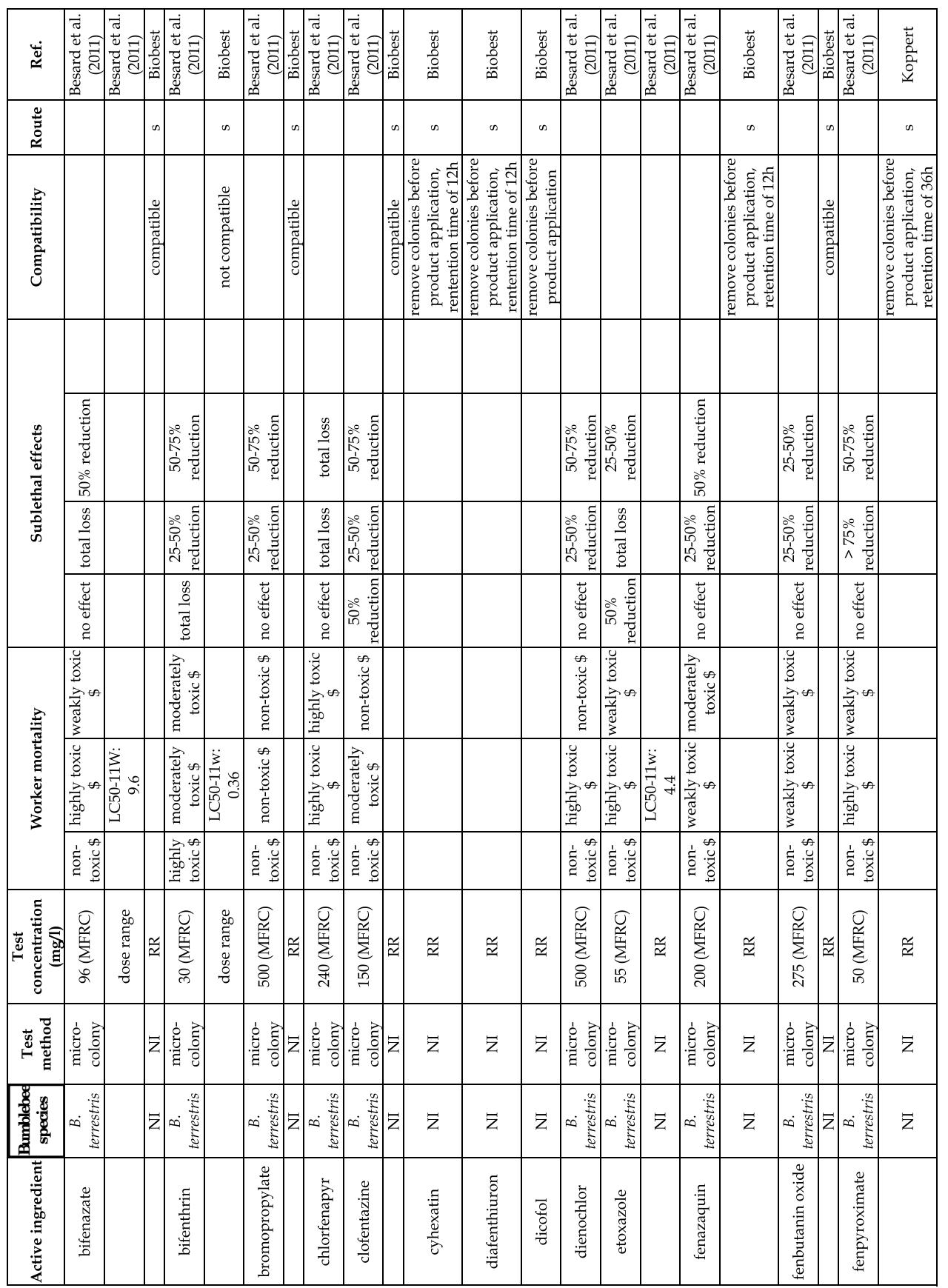

Table 2. Continued 


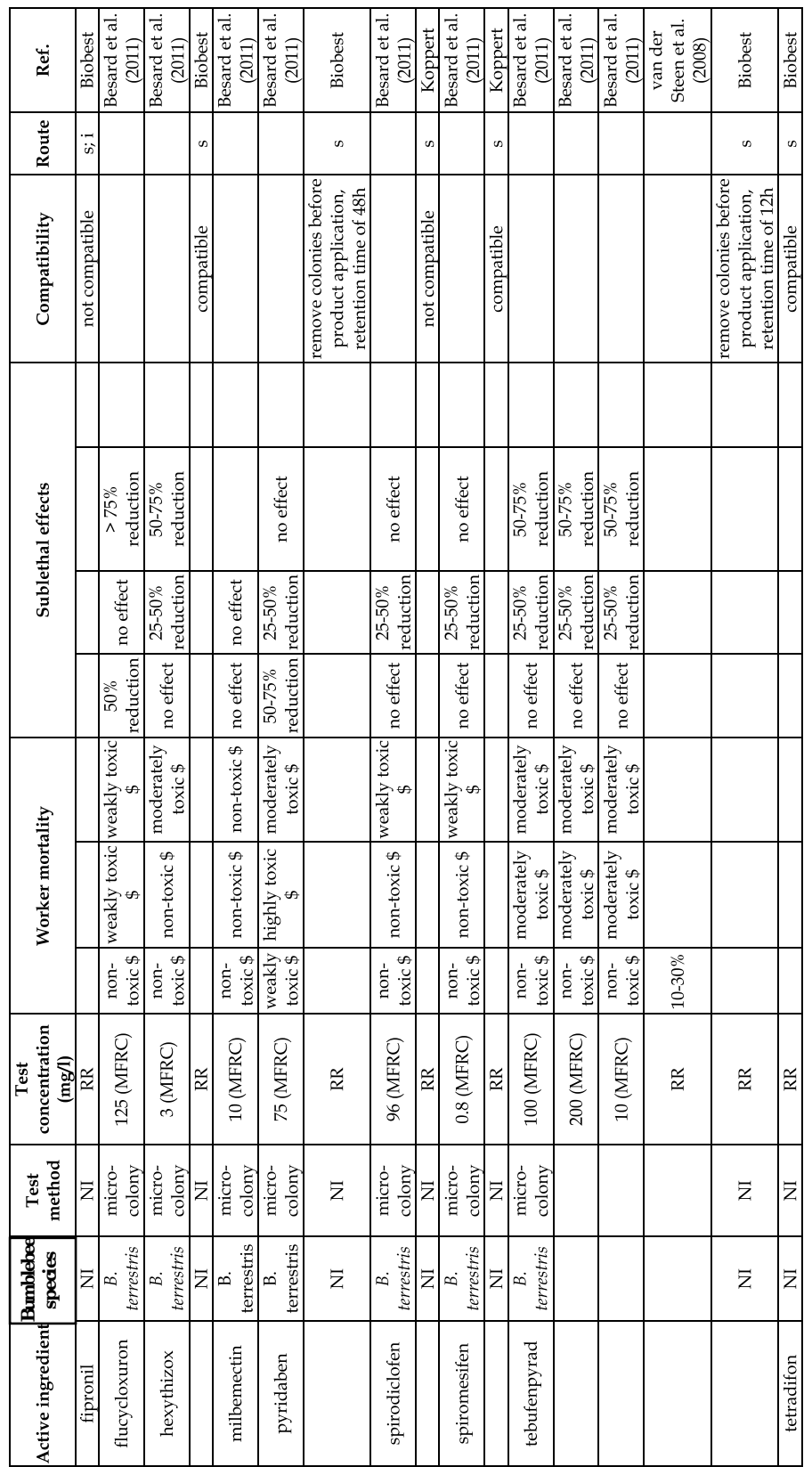

Table 2. Overview of the toxicity of acaricides towards Bombus species, (NI: no information; RR: recommended rate; \$: toxicity according to the IOBC classification for extended laboratory tests; * toxicity according to the IOBC classification for laboratory studies; $£$ : compatibility according to the side-effect list; Route ( $\mathrm{s}=$ spraying, $\mathrm{i}=$ irrigation) 


\begin{tabular}{|c|c|c|c|c|c|c|c|c|c|c|c|c|c|c|c|c|}
\hline$\stackrel{\ddot{\Xi}}{\dddot{\Xi}}$ & & & 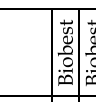 & 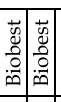 & 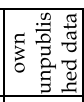 & 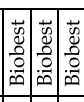 & 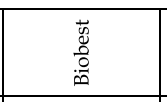 & 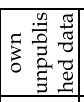 & 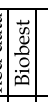 & 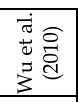 & 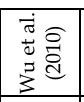 & 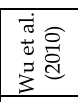 & 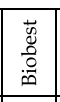 & 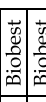 & . & 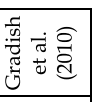 \\
\hline 莺 & & & $\infty$. & $\infty \begin{array}{lll}\infty & \infty\end{array}$ & & 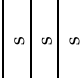 & is & & $\infty$ & & & & $\infty$ & $\infty$ & is & \\
\hline 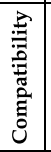 & & & 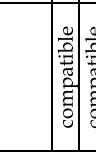 & 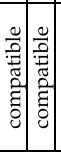 & & 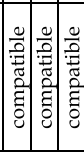 & 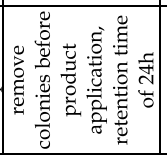 & & 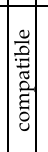 & & & & 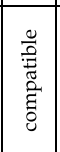 & : & 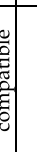 & \\
\hline \multirow{5}{*}{ 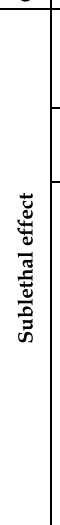 } & 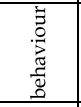 & & & & & & & & & & & & & & & \\
\hline & $\begin{array}{l}\vec{J} \\
\frac{5}{\sigma} \\
\end{array}$ & & & & & & & & & & & & & & & \\
\hline & \multirow{3}{*}{ 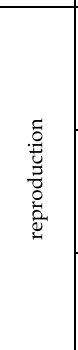 } & 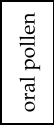 & & & 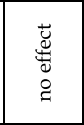 & & & 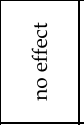 & & & & & & & & \\
\hline & & 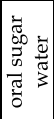 & & & 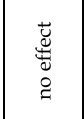 & & & 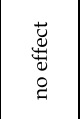 & & & & & & & & \\
\hline & & $\begin{array}{l}\overrightarrow{\tilde{U}} \\
\tilde{\tilde{g}} \\
\tilde{\delta}\end{array}$ & & & 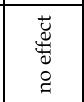 & & & 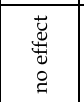 & & & & & & & & \\
\hline \multirow{3}{*}{ 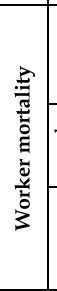 } & 写总 & & & & 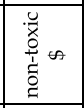 & & & 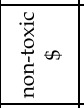 & & & & & & & & \\
\hline & 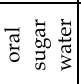 & & & & 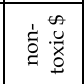 & & & 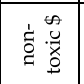 & & & & & & & & \\
\hline & 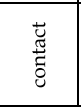 & & & & 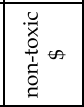 & & & 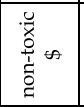 & & 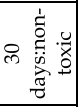 & 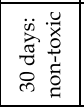 & 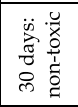 & & & & 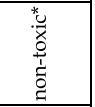 \\
\hline | & 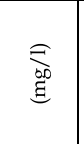 & & $\approx$ & $\approx \approx$ & 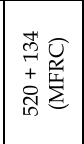 & $\approx|\approx| \approx n$ & $\cong$ & $\begin{array}{l}\text { 量 } \\
\text { in } \\
\text { to } \\
\text { in } \\
\text { in }\end{array}$ & $\approx$ & 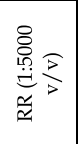 & & & $\cong$ & $\approx$ & $\frac{\pi}{a}$ & 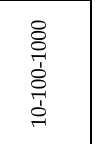 \\
\hline 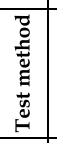 & & & & $\bar{z} \mathbf{z}$ & 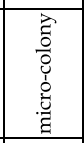 & $\bar{z} \bar{z}$ & z & 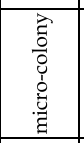 & $\mathrm{z}$ & 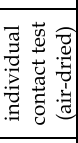 & 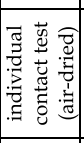 & 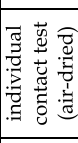 & z & $z$ & 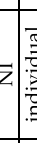 & 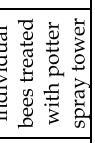 \\
\hline 空 & & & $\bar{z}$ & $\bar{z} \mid z$ & 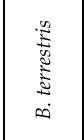 & $\bar{z} \mid \bar{z}$ & $\bar{z}$ & 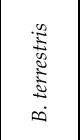 & $\bar{z}$ & 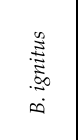 & 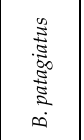 & 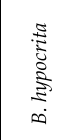 & $\bar{z}$ & $\bar{z} \mid \bar{z}$ & z. & 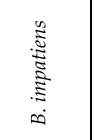 \\
\hline 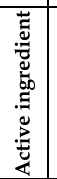 & & & 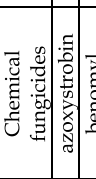 & 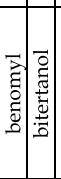 & 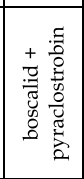 & 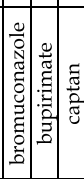 & 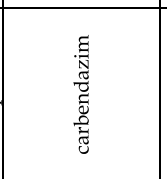 & 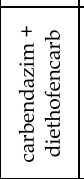 & 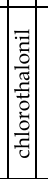 & 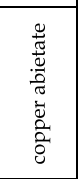 & & & 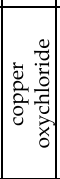 & & |ֶ: & 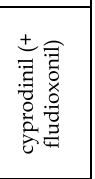 \\
\hline
\end{tabular}

Table 3. Continued 


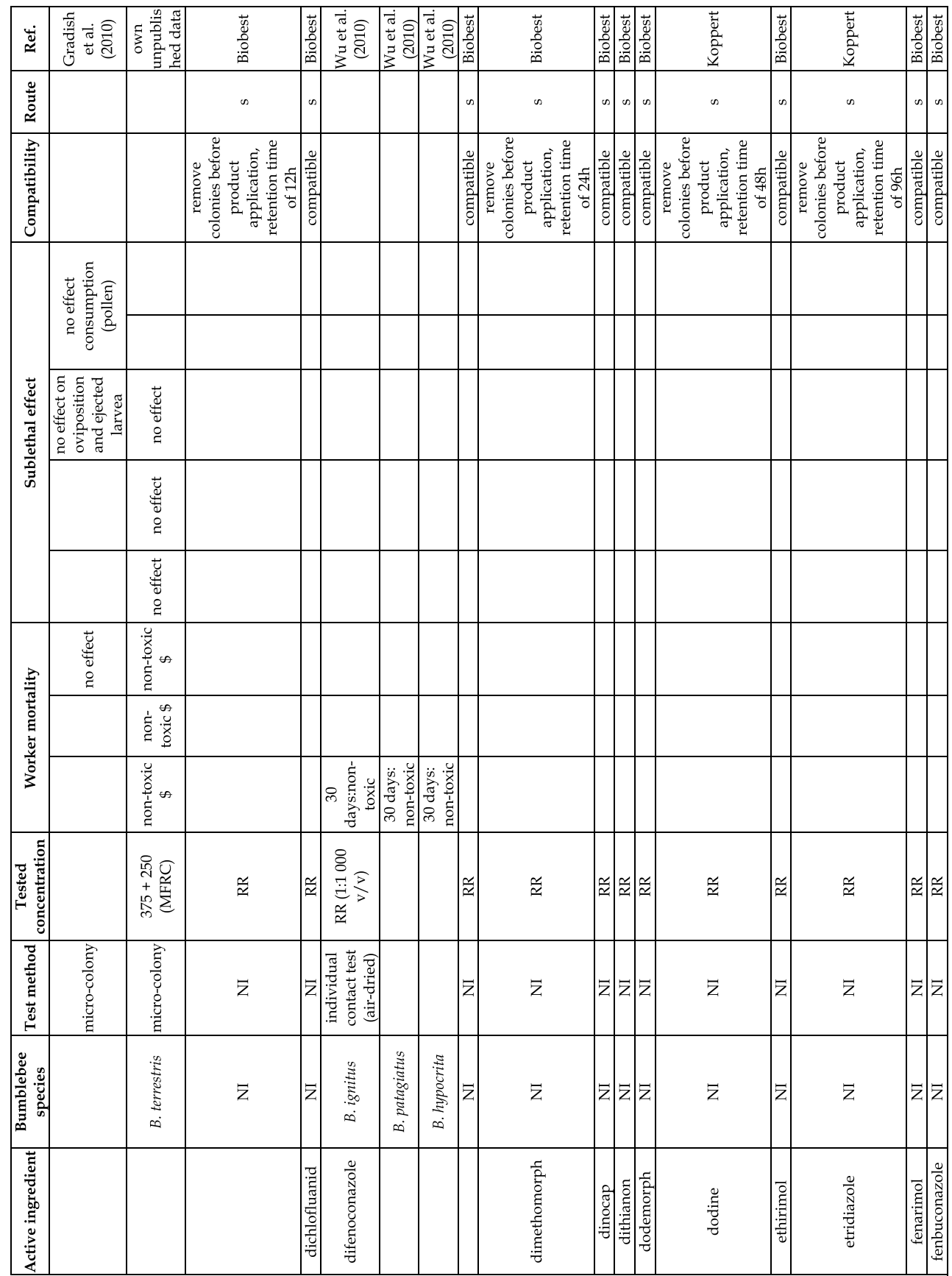

Table 3. Continued 


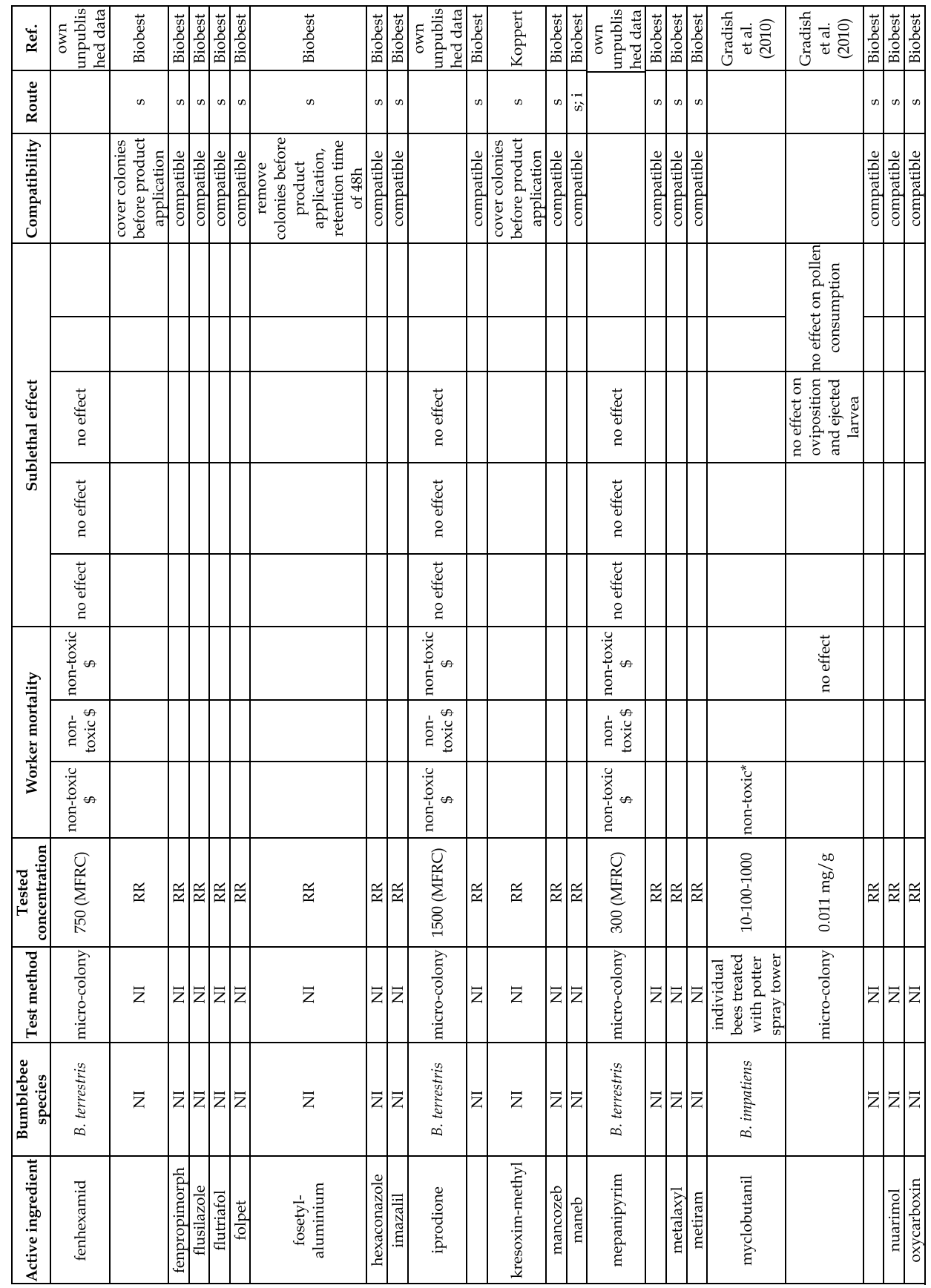

Table 3. Continued 


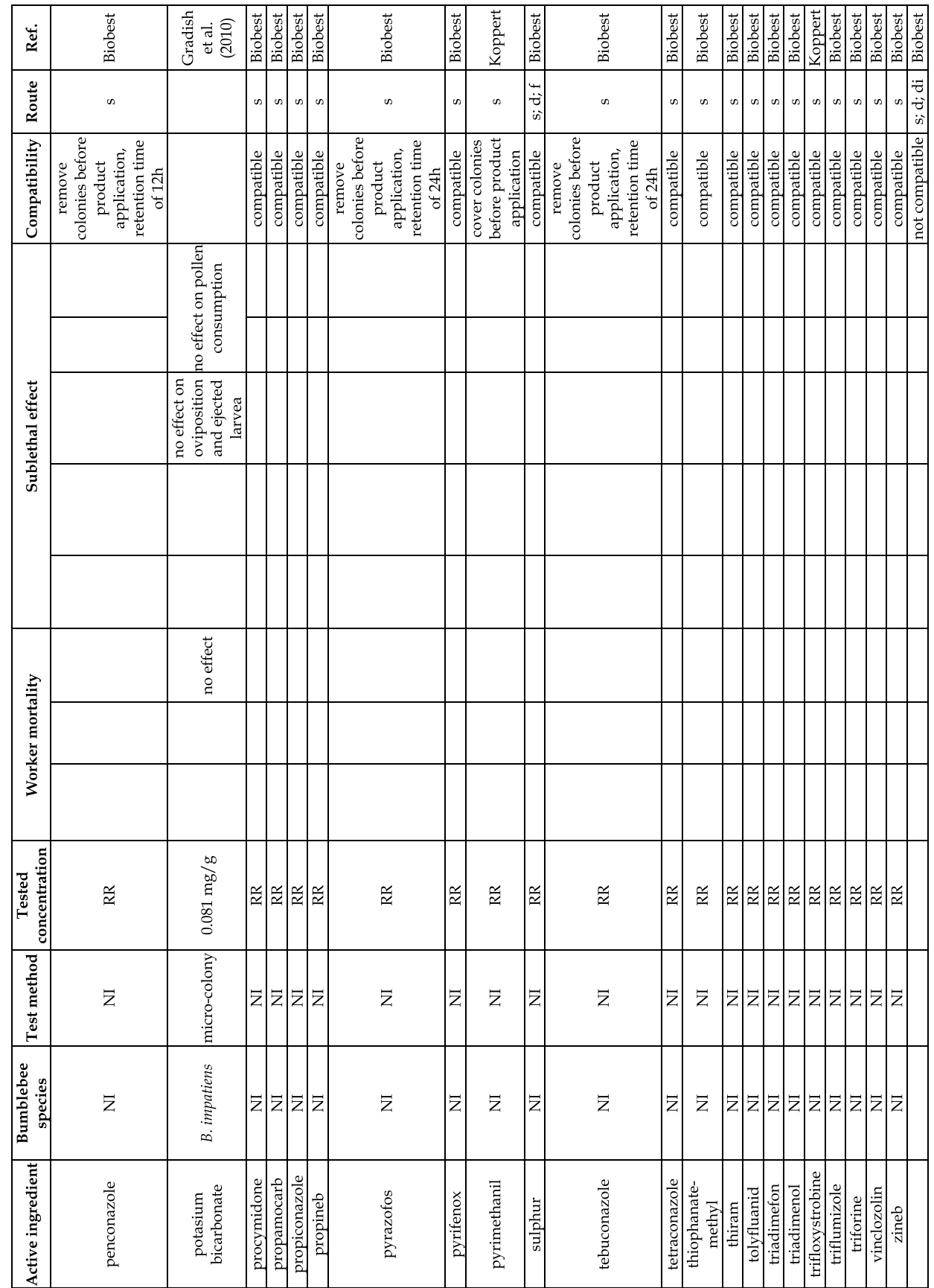

Table 3. Continued 


\begin{tabular}{|c|c|c|c|c|c|c|c|c|c|c|c|c|}
\hline$\ddot{\Xi}$ & & 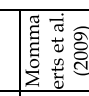 & 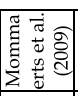 & 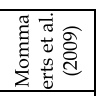 & 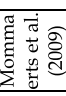 & 㞼 & 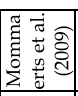 & 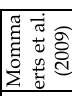 & 采焉 & 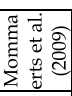 & 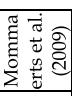 & 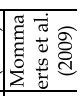 \\
\hline 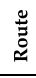 & & & & & & & & & & & & \\
\hline : & & & & & & & & & & & & \\
\hline \multirow{4}{*}{ 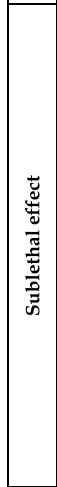 } & & & 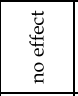 & & & & 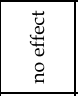 & & 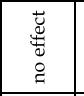 & & & 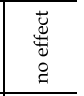 \\
\hline & & 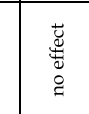 & & 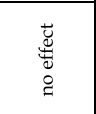 & 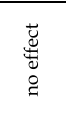 & 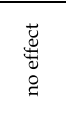 & & 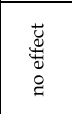 & & 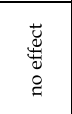 & 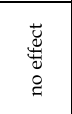 & \\
\hline & & 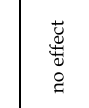 & 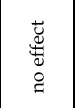 & 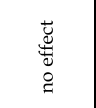 & 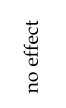 & 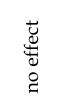 & $\begin{array}{l}\text { 总 } \\
\text { dै } \\
0 \\
0\end{array}$ & 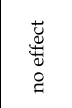 & 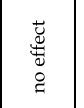 & $\begin{array}{l}\frac{n}{0} \\
\frac{8}{5} \\
\frac{\pi}{2}\end{array}$ & 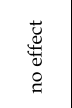 & 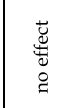 \\
\hline & & 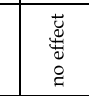 & & 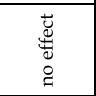 & 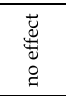 & 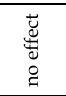 & & 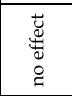 & & 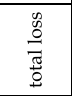 & 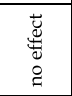 & \\
\hline \multirow{3}{*}{ 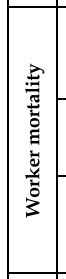 } & & 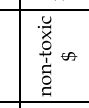 & & 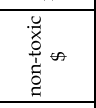 & 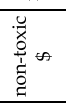 & 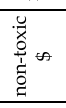 & & 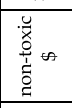 & & 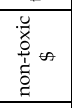 & 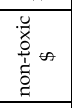 & \\
\hline & & 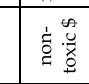 & 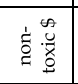 & 㝘部 & 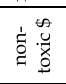 & 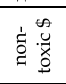 & 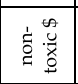 & 它 & 立离 & 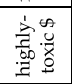 & 妾 & 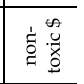 \\
\hline & & 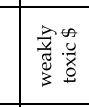 & & 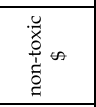 & 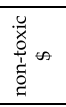 & 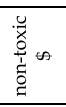 & & 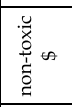 & & 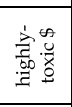 & 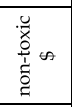 & \\
\hline $\begin{array}{ll}0 \\
0 \\
0\end{array}$ & & 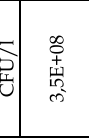 & & 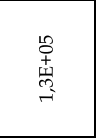 & 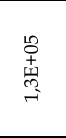 & 总 & & $\begin{array}{l}\text { 象 } \\
\text { 产 } \\
\text { 点 }\end{array}$ & & 故 & 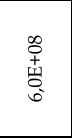 & \\
\hline 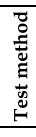 & & 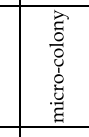 & \begin{tabular}{|ll} 
& \\
\\
0
\end{tabular} & 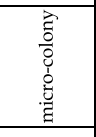 & 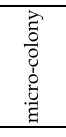 & 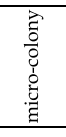 & 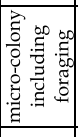 & 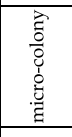 & 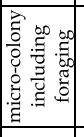 & 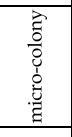 & 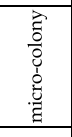 & 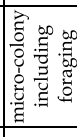 \\
\hline 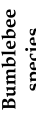 & & 宽 & & 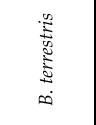 & 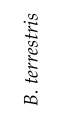 & 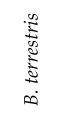 & & 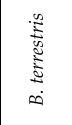 & & 莃 & 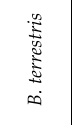 & \\
\hline 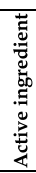 & 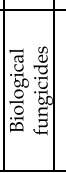 & 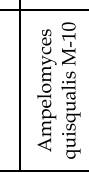 & & 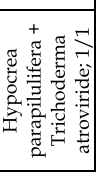 & & & & 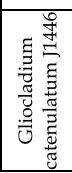 & & 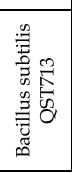 & 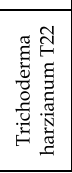 & \\
\hline
\end{tabular}

Table 3. Overview of the toxicity of fungicides towards Bombus species, (NI: no information; RR: recommended rate; $\$$ : toxicity according to the IOBC classification for extended laboratory tests; * toxicity according to the IOBC classification for laboratory studies; $€$ : compatibility according to the side-effect list; Route (s=spraying, $\mathrm{i}=$ irrigation, $\mathrm{d}=\mathrm{d}$ usting, $\mathrm{di}=$ dipping; $\mathrm{f}=$ fumigation ) 
standardized (selection of a particular instar for exposure) and to test more concentrations in parallel. Similarly, also the field of behavioral changes lacks proper laboratory methods to assess behavioral changes in a lower tier. Here the development of a PER bioassay would allow to assess the impact on the memory and learning capacity of individual insects already in "tier 1". Furthermore, it is likely that also other endpoints will be identified for risk assessments due to the increasing knowledge of the insect body and its processes and because it is to be expected that new active substance will be found with other modes of action.

The obtained data showed that older insecticides (carbamates, pyrethroids and organophosphates) are more toxic than novel insecticides (IGRs, neonicotinoids and biological insecticides). Also low hazards can be expected based on the data for fungicides, whereas for the acaricides the side-effects are strongly dependent on the route of exposure. In addition, it was clear that over the different groups of PPPs bumblebees are in general less sensitive to pesticide toxicity than honeybees. However, the power of the linear regression between the $\mathrm{LD}_{50}-24 \mathrm{~h}$ values of 17 insecticides in $B$. terrestris versus honeybees was poor. In conclusion, the identification and especially the knowledge of the consequences of sublethal effects for populations will lead to the development of IPM programs with low risks for pollinators. Reaching all these goals may be of little help if they are not accompanied by a proper communication with cultivators and farmers in the field.

\section{Acknowledgements}

This research project was supported in part by the Research Council of VUB (Brussels Belgium), the Special Research Council of Ghent University, and the Fund for Scientific Research (FWO-Vlaanderen, Brussels).

\section{References}

Aldershof, S. (1999). Determination of the acute contact $\mathrm{LD}_{50}$ of spinosad (formulated as the 480 G/LSC, NAF-85) for the bumblebee Bombus terrestris L. Report GHE-P-7875, Dow AgroSciences, Indianapolis, IN.

Babendreier, D.; Reichhart, B.; Romeis, J. \& Bigler, F. (2008). Impact of insecticidal proteins expressed in transgenic plants on bumblebee microcolonies. Entomologia Experimentalis et Applicata, Vol. 126, No. 2, (February 2008), pp.148-157, ISSN 15707458

Besard, L.; Mommaerts, V.; Vandeven, J.; Cuvelier, X.; Sterk, G. \& Smagghe, G. (2010). Compatibility of traditional and novel acaricides with bumblebees (Bombus terrestris): a first laboratory assessment of toxicity and sublethal effects. Pest Management Science, Vol. 66, No. 7, (July 2010), pp. 786-793, ISSN 1526-4998

Besard, L.; Mommaerts, V.; Abdu-Alla, G. \& Smagghe, G. (2011). Laboratory assessment of lethal and sublethal side-effects supports a more benign profile of spinetoram compared to spinosad in the bumblebee Bombus terrestris. Pest Management Science, Vol.67, No. 5, (May 2011), pp.541-547, ISSN 1526-498x

Biobest N.V. Side-effect list, 01.04.2011, Available from http:/ / www.biobest.be

Colin, ME.; Le Conte, Y. \& Vermandere, JP. (2001). Managing nuclei in insect-proof tunnel as an observation tool for foraging bees, In: Hazards of Pesticides to Bees Sublethal 
effects of deltamethrin and imidacloprid, Belzunces LP, Pélissier C, Lewis GB (eds.), pp 259-268, INRA, Paris.

de Wael, L.; de Greef, M. \& van Laere, O. (1995). Toxicity of pyriproxifen and fenoxycarb to bumble bee brood using a new method for testing insect growth regulators. eburnal of Apicultural Research, Vol. 34, No.1, (January 1995), pp.3-8, ISSN 2078-6913

Decoutye, A. \& Pham-Delègue, MH. (2002). The proboscis extension response: assessing the sublethal effects of pesticides on the honey bee. In: Honey bees: estimating the environmental impact of chemicals, Devillers, J. \& Pham-Delègue, MH. (eds), pp 67-84, Taylor and Francis, ISBN 041-5275-18-0, London.

Decourtye, A.; Lacassie, E. \& Pham-Delègue, MH. (2003). Learning performances of honeybees (Apis mellifera L.) are differentially affected by imidacloprid according to the season. Pest Management Science, Vol. 59, No. 3, (March 2003), pp. 269-278, ISSN $1526-4998$

Decourtye, A.; Armengaud, C.; Renou, M.; Devillers, J.; Cluzeau, S.; Gauthier, M. \& PhamDelègue, MH. (2004a). Imidacloprid impairs memory and brain metabolism in the honeybee (Apis mellifera L.). Pesticide Biochemistry and Physiology, Vol. 78, No. 2, (February 2004), pp. 83-92, ISSN 0048-3575

Decourtye, A.; Devillers, J.; Cluzeau, S. ; Charaton, M. \& Pham-Delègue, MH. (2004b). Effects of imidacloprid and deltamethrin on associative learning in honeybees under semi-field and laboratory conditions. Ecotoxicology and Environmental Safety, Vol. 57, No. 3, (March 2004), pp. 410-419, ISSN 0147-6513

Desneux, N.; Decourtye, A. \& Delpuech, JM. (2007). The sublethal effects of pesticides on beneficial arthropods. Annual Review of Entomology, Vol. 52, (January 2007), pp. 81106, ISSN 0066-4170

El Hassani, AK.; Dacher, M.; Garry, V.; Lambin, M.; Gauthier, M. \& Armengaud, C. (2008). Effects of sublethal doses of acetamiprid and thiamethoxam on the behavior of the honeybee (Apis mellifera). Archives of Environmental Contamination and Toxicology, Vol. 54, No. 4, (May 2008), pp. 653-661, ISSN 1432-0703

Gallai, N.; Salles, J-M.; Settele, J. \& Vaissière, BE. (2009). Economic valuation of the vulnerability of world agriculture confronted with pollinator decline. Ecological Economics, Vol. 68, No. 3, (January 2009), pp. 810-821, ISSN 0921-8009

Gels, JA.; Held, DW. \& Potter, DA. (2002). Hazards of insecticides to the bumble bees Bombus impatiens (Hymenoptera: Apidae) foraging on flowering white clover in turf. eburnal of Economic Entomology, Vol. 95, No. 4, (August 2002), pp. 722-728, ISSN 0022-0493

Goulson, D.; Lye, GC. \& Darvill, B. (2008). Decline and conservation of bumble bees. Annual Review of Entomology, Vol. 53, (January 2008), pp. 191-208, ISSN 0066-4170

Goulson, D. (2010). Bumblebees behaviour, ecology and conservation. Oxford University Press, ISBN 019-9553-07-6, New York.

Gradish, AE.; Scott-Dupree, DC.; Shipp, L.; Harris, CR. \& Ferguson, G. (2010). Effect of reduced risk pesticides for use in greenhouse vegetable on Bombus impatiens (Hymenoptera: Apidae). Pest Management Science, Vol. 66, No. 2, (February 2010), pp. 142-146, ISSN 1526-4998

Gretenkord, C. \& Dresher, W. (1993). Effects of four pesticides (Decis, Metasystox, Pirimor, Rubitox) on the bumblebee Bombus terrestris L.: determination of the oral $\mathrm{LD}_{50}$ and 
preliminary results with field tests. Apidologie, Vol. 24, No. 5, (March 2003), pp. 519520, ISSN 1297-9678

Gretenkord, K. \& Drescher, W. (1996). Laboratory and cage test methods for the evaluation of the effects of insect growth regulators (Insegar, Dimilin) on the brood of Bombus terrestris. Proceedings of 6th International Sympymposium Hazards of Pesticides to Bees, Braunschweig, Germany, September 1996

Halsall, N. \& Grey, AP. (1998). NAF-85 (480 g/1 SC of spinosad): acute toxicity to honeybees. Report GHE-T-850, Dow AgroSciences, Indianapolis, IN.

Hardstone, MC. \& Scott, JG. (2010). Is Apis more sensitive to insecticides than other insects? Pest Management Science, Vol. 66, No. 11, (November 2010), pp. 1171-1180, ISSN 1526-498X

Heinrich, B. (1979). Bumblebee Economics. Harvard University Press, ISBN 067-4016-39-4, London, England

Hokkanen, H.; Zeng, QQ. \& Menzler-Hokkanen, I. (2004). Assessing the impact of Metarhizium and Beauveria on bumblebees In: Progress in Biological Control: Environmental Impacts of Microbial Insecticides, Needs and Methods for Risk Assessment, Hokkanen, H. \& Hajek, EA. (eds.), pp 63-72, Kluwer Academic Publishers, ISBN 140-2008-13-9, Dordrecht, The Netherlands

Incerti, F.; Bortolotti, L.; Porrini, C.; Sbrenna, AM. \& Sbrenna, G. (2003). An extended laboratory test to evaluate the effects of pesticides on bumblebees. Preliminary results. Bulletin of Insectology, Vol. 56, No. 1, pp. 156-164, ISSN 1721-8861

Koppert B.V. Side-effect list, 01.04.2011, Available from http://neveneffecten.koppert.nl/

Marletto, F.; Patetta, A. \& Manino, A. (2003). Laboratory assessment of pesticide toxicity to bumblebees. Bulletin of Insectology, Vol. 56, No. 1, pp. 155-158, ISSN 1721-8861

Mayes, MA.; Thompson, GD., Husband, B. \& Miles, MM. (2003). Spinosad toxicity to pollinators and associated risk. Reviews of Environmental Contamination and Toxicology, Vol., 179, pp. 37-71, ISSN 0179-5953

Mommaerts, V.; Sterk, G. \& Smagghe, G. (2006a). Hazards and uptake of chitin synthesis inhibitors in bumblebees Bombus terrestris. Pest Management Science, Vol. 62, No. 8, (August 2006), pp. 752-758, ISSN 1526-4998

Mommaerts, V.; Sterk, G. \& Smagghe, G. (2006b). Bumblebees can be used in combination with juvenile hormone analogues and ecdysone agonists. Ecotoxicology, Vol. 15, No. 6, (August 2006), pp. 513-521, ISSN 0963-9292

Mommaerts, V.; Platteau, G.; Boulet, J.; Sterk, G. \& Smagghe, G. (2008). Trichoderma-based biological control agents are compatible with the pollinator Bombus terrestris: A laboratory study. Biological Control, Vol. 46, No. 3, (September 2008), pp. 463-466, ISSN 1049-9644

Mommaerts, V.; Sterk, G.; Hoffmann, L. \& Smagghe, G (2009). A laboratory evaluation to determine the compatibility of microbiological control agents with the pollinator Bombus terrestris. Pest Management Science, Vol. 65, No. 9, (September 2009), pp. 949955, ISSN 1526-4998

Mommaerts, V.; Jans, K. \& Smagghe, G. (2010a). Impact of Bacillus thuringiensis strains on survival, reproduction and foraging behaviour in bumblebees (Bombus terrestris). Pest Management Science, Vol. 66, No. 5, (May 2010), pp. 520-525, ISSN 1526-4998

Mommaerts, V.; Reynders, S.; Boulet, J.; Besard, L.; Sterk, G. \& Smagghe, G. (2010b) Risk assessment for side-effects of neonicotinoids against bumblebees with and without 
impairing foraging behaviour. Ecotoxicology, Vol. 19, No. 1, (January 2010), pp. 207215, ISSN 0963-9292

Morandin, LA. \& Winston, ML. (2003). Effects of novel pesticides on bumblebee (Hymenoptera: Apidae) colony and foraging ability. Environmental Entomology, Vol. 32, No. 3, (June 2003), pp. 555-563, ISSN 0046-225X

Morandin, LA.; Winston, ML.; Franklin, MT. \& Abott, VA. (2005). Lethal and sub-lethal effects of spinosad on bumble bees (Bombus impatiens Cresson). Pest Management Science, Vol. 61, No. 7, (July 2005), pp. 619-626, ISSN 1526-4998

Mullin, CA.; Frazier, M.; Frazier, JL.; Ashcraft, S.; Simonds, R.; van Engelsdorp, D. \& Pettis, JS. (2010). High levels of miticides and agrochemicals in North American apiaries: implications for honey bee health. PLoS ONE, Vol. 5, No. 3, (March 2010), pp. e9754, ISSN 1932-6203

Riveros, AJ. \& Gronenberg, W. (2009). Olfactory learning and memory in the bumblebee Bombus occidentalis. Naturwissenschaften, Vol. 96, No. 7, (July 2009), pp. 851-856, ISSN 0028-1042

Schaefer, H. \& Mülhen, W. (1996). Erste Erfarungen zur Prüfung der Auswirkungen des Pflanzenschuzmittels Alsystin an der erdhummel Bombus terrestris L. im freiland. Apidologie, Vol. 27, No. 4, pp. 273-275, ISSN 1297-9678

Scott-Dupree, CD.; Conroy, L. \& Harris, R. (2009). Impact of currently used or potentially useful insecticides for canola agroecosystems on Bombus impatiens (Hymenoptera: Apidae), Megachile rotundata (Hymenoptera: Megachilidae), and Osmia lignaria (Hymenoptera: Megachilidae). eburnal of Economic Entomology, Vol. 102, No. 1, (February 2009), pp. 177-182, ISSN 0022-0493

Sechser, B. \& Reber, B. (1996). Using a sequential testing scheme under laboratory and field conditions with the bumblebee Bombus terrestris to evaluate the safety of different groups of insecticides. Proceedings of Conference Ecotoxicology Pesticides and Beneficial Organisms, Cardiff, Wales, UK, October 1996

Skerl, MS.; Bolta, SV.; Cesnik, HB. \& Gregorc, A. (2009). Residues of pesticides in honeybee (Apis mellifera carnica) bee bread and in pollen loads from treated apple orchards. Bulletin of Environmental Contamination and Toxicology, Vol. 83, No. 3, (September 2009), pp. 374-377, ISSN 0007-4861

Tasei, JN.; Sabik, H.; Piratsu, L.; Langiu, E.; Blanche, JM.; Fournier, J. \& Taglioni, JP. (1993). A sequential study on the effects of deltamethrin (Decis CE) on bumble bees. Proceedings of the $5^{\text {th }}$ International Symposium Hazard of Pesticides to Bees, Wageningen, The Netherlands, October 1993.

Tasei, JN.; Sabik, H. \& Pirastru, L. (1994). Effects of sublethal doses of deltamethrin (DecisCE) on Bombus terrestris. eburnal of Apicultural Research, Vol. 33, No. 3, (1994), pp. 129-135, ISSN 0021-8839

Tasei, JN.; Lerin, J. \& Ripault, G. (2000). Sub-lethal effects of imidacloprid on bumblebees, Bombus terrestris (Hymenoptera: Apidae), during a laboratory feeding test. Pest Management Science, Vol. 56, No. 9, (September 2000), pp. 784-788, ISSN 1526-498X

Tasei, JN.; Ripault, G. \& Rivault, E. (2001). Hazards of imidacloprid seed coating to Bombus terrestris (Hymenoptera: Apidae) when applied to sunflower. eburnal of Economic Entomology, Vol. 94, No. 3, (June 2001), pp. 623-627, ISSN 0022-0493 
Tasei, JN. (2001). Effects of insect growth regulators on honey bees and non-Apis bees. A review. Apidologie, Vol. 32, No. 6, (November-December 2001), pp. 527-545, ISSN 0044-8435

Thompson, MH. \& Hunt, LV. (1999). Extrapolating from honeybees to bumblebees in pesticide risk assessments. Ecotoxicology, Vol. 8, No. 3, (June 1999), pp. 147-166, ISSN 0963-9292

Thompson, HM. (2001). Assessing the exposure and toxicity of pesticides to bumblebees (Bombus sp.) Apidologie, Vol. 32, No. 4, (July-August 2001), pp. 305-321, ISSN 00448435

Thompson, HM. (2003). Behavioural effects of pesticides in bees-their potential for use in risk assessment. Ecotoxicology, Vol. 12, No. 1-4, (February-August 2003), pp. 317330, ISSN 0963-9292

Thompson, HM.; Wilkins, S.; Battersby, AH.; Waite; RJ. \& Wilkinson, D. (2005). The effects of four insect growth-regulating (IGR) insecticides on honeybee (Apis mellifera L.) colony development, queen rearing and drone sperm production. Ecotoxicology, Vol. 14, No. 7, (October 2005), pp. 757-769, ISSN 0963-9292

Toxicity data of PPPs for honeybees used in figure 3, 31.03.2011, Available from http:// sitem.herts.ac.uk/aeru/footprint/en/index.htm

van der Steen, JJM. (1994). Method development for the determination of the contact $\mathrm{LD}_{50}$ of pesticides to bumblebees (Bombus terrestris L.). Apidologie, Vol. 24, No. 5, (1993), pp. 463-465, ISSN 1297-9678

van der Steen, JM. (2001) Review of the methods to determine hazards and toxicity of pesticides to bumblebees. Apidologie, Vol. 32, No. 5, (September-October 2001), pp. 399-406, ISSN 0044-8435

van der Steen, JJM. (2005). Bumble bee brood subgroup report. $9^{\text {th }}$ International Symposium Hazard of Pesticides to Bees, York, UK, October 2005 (abstract).

van der Steen, JJM.; Bortolotti, L. \& Chauzat, MP. (2008). Can pesticide acute toxicity for bumblebees be derived from honeybees $\mathrm{LD}_{50}$-values? 10 $0^{\text {th }}$ International Symposium Hazard of Pesticides to Bees, Bucharest, Romania October 2008 (Abstract).

Van Engelsdorp, D.; Evans, J.; Saergerman, C.; Mullin, C.; Haubruge, E.; Nguyen, BK.; Frazier, M.; Frazier, J.; Cox-Foster, D.; Chen, YP.; Underwood, R.; Tarpy, DR. \& Pettis, JS. (2009). Colony collapse disorder: a descriptive study. PLoS ONE, Vol. 4, No. (August 2009), pp. e6481, ISSN 1932-6203

Velthuis, HHW. \& van Doorn, A. (2006). A century of advances in bumblebee domestication and the economic and environmental aspects of its commercialization for pollination. Apidologie, Vol. 37, No. 4, (July-August 2006), pp. 421-451, ISSN 00448435

Wu, J.; Li, j-M.; Peng, W-J. \& Hu, F-L. (2010). Sensitivities of three bumblebee species to four pesticides applied commonly in greenhouses in China. Insect Science, Vol. 17, No. 1, (February 2010), pp. 67-72, ISSN 1672-9609

Wu, JY.; Anelli, CM. \& Sheppard, WS. (2011). Sub-lethal effects of pesticide residues in brood comb on worker honey bee (Apis mellifera) development and longevity. PLoS ONE, Vol. 6, No. 2, (February 2011), pp. e14720, ISSN 1932-6203 


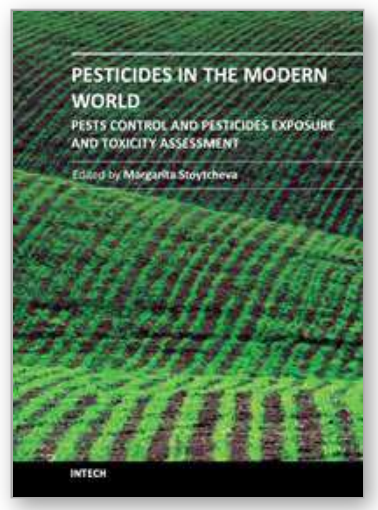

\section{Pesticides in the Modern World - Pests Control and Pesticides Exposure and Toxicity Assessment}

Edited by Dr. Margarita Stoytcheva

ISBN 978-953-307-457-3

Hard cover, 614 pages

Publisher InTech

Published online 30, September, 2011

Published in print edition September, 2011

The present book is a collection of selected original research articles and reviews providing adequate and upto-date information related to pesticides control, assessment, and toxicity. The first section covers a large spectrum of issues associated with the ecological, molecular, and biotechnological approaches to the understanding of the biological control, the mechanism of the biocontrol agents action, and the related effects. Second section provides recent information on biomarkers currently used to evaluate pesticide exposure, effects, and genetic susceptibility of a number of organisms. Some antioxidant enzymes and vitamins as biochemical markers for pesticide toxicity are examined. The inhibition of the cholinesterases as a specific biomarker for organophosphate and carbamate pesticides is commented, too. The third book section addresses to a variety of pesticides toxic effects and related issues including: the molecular mechanisms involved in pesticides-induced toxicity, fish histopathological, physiological, and DNA changes provoked by pesticides exposure, anticoagulant rodenticides mode of action, the potential of the cholinesterase inhibiting organophosphorus and carbamate pesticides, the effects of pesticides on bumblebee, spiders and scorpions, the metabolic fate of the pesticide-derived aromatic amines, etc.

\section{How to reference}

In order to correctly reference this scholarly work, feel free to copy and paste the following:

Veerle Mommaerts and Guy Smagghe (2011). Side-Effects of Pesticides on the Pollinator Bombus: An Overview, Pesticides in the Modern World - Pests Control and Pesticides Exposure and Toxicity Assessment, Dr. Margarita Stoytcheva (Ed.), ISBN: 978-953-307-457-3, InTech, Available from:

http://www.intechopen.com/books/pesticides-in-the-modern-world-pests-control-and-pesticides-exposure-andtoxicity-assessment/side-effects-of-pesticides-on-the-pollinator-bombus-an-overview

\section{INTECH}

open science | open minds

\author{
InTech Europe \\ University Campus STeP Ri \\ Slavka Krautzeka 83/A \\ 51000 Rijeka, Croatia \\ Phone: +385 (51) 770447 \\ Fax: +385 (51) 686166 \\ www.intechopen.com
}

\author{
InTech China \\ Unit 405, Office Block, Hotel Equatorial Shanghai \\ No.65, Yan An Road (West), Shanghai, 200040, China \\ 中国上海市延安西路65号上海国际贵都大饭店办公楼 405 单元 \\ Phone: +86-21-62489820 \\ Fax: +86-21-62489821
}


(C) 2011 The Author(s). Licensee IntechOpen. This chapter is distributed under the terms of the Creative Commons Attribution-NonCommercialShareAlike-3.0 License, which permits use, distribution and reproduction for non-commercial purposes, provided the original is properly cited and derivative works building on this content are distributed under the same license. 